\title{
It's All Fun and Games until Somebody Dies: Grief, Mortality Salience, and Coping in Meaningful Permadeath
}

\author{
Mckay Steven West \\ West Virginia University, Mckay.Steven.West@gmail.com
}

Follow this and additional works at: https://researchrepository.wvu.edu/etd

Part of the Communication Technology and New Media Commons

\section{Recommended Citation}

West, Mckay Steven, "It's All Fun and Games until Somebody Dies: Grief, Mortality Salience, and Coping in Meaningful Permadeath" (2020). Graduate Theses, Dissertations, and Problem Reports. 7614.

https://researchrepository.wvu.edu/etd/7614

This Dissertation is protected by copyright and/or related rights. It has been brought to you by the The Research Repository @ WVU with permission from the rights-holder(s). You are free to use this Dissertation in any way that is permitted by the copyright and related rights legislation that applies to your use. For other uses you must obtain permission from the rights-holder(s) directly, unless additional rights are indicated by a Creative Commons license in the record and/ or on the work itself. This Dissertation has been accepted for inclusion in WVU Graduate Theses, Dissertations, and Problem Reports collection by an authorized administrator of The Research Repository @ WVU.

For more information, please contact researchrepository@mail.wvu.edu. 
It's All Fun and Games until Somebody Dies: Grief, Mortality Salience, and Coping in Meaningful Permadeath

\title{
Mckay Steven West
}

\author{
Dissertation submitted \\ to the Eberly College of Arts and Sciences \\ at West Virginia University \\ in partial fulfillment of the requirements of the degree of \\ Doctor of Philosophy \\ in Communication Studies
}

\author{
Elizabeth L. Cohen, Ph.D., Chair \\ Jaime Banks, Ph.D. \\ Alan K. Goodboy, Ph.D. \\ Liesel L. Sharabi, Ph. D. \\ Department of Communication Studies
}

\author{
Morgantown, West Virginia \\ 2020
}

Keywords: Permadeath, Grief, Mortality Salience, Meaning Making, Appreciation

Copyright 2020 Mckay Steven West 


\begin{abstract}
It's All Fun and Games until Somebody Dies: Grief, Mortality Salience, and Coping in Meaningful Permadeath
\end{abstract}

Mckay Steven West

Because part of the enjoyment of video game experiences is rooted in their ability to afford players to fail but still reattempt gameplay with relatively little consequence, the appeal of playing games with permadeath seems paradoxical. This dissertation proposed that players' motivations for playing these games with permadeath stem from an enhanced sense of appreciation garnered by players through the meaningfulness of permanent character death, rather than just through simple, hedonic enjoyment. Enhanced appreciation was expected to arise from permadeath through the grief players experienced toward the loss of their characters and through their contemplation of their own mortality. Grief was anticipated to be higher for players with stronger parasocial relationships to their characters while mortality salience was anticipated to be higher for players who identified with those game characters, and all indirect effects were expected to be moderated by players' trait meaning making coping style. Participants $(N=394)$ were players recruited from various gaming subreddits on Reddit.com who had previous experiences playing permadeath games. In an online survey, they were assigned to either report on their impressions of a permadeath or a temporary character death that they had experienced in the past year. Two conditional process analyses revealed that players did report increased appreciation - through their grief for their characters - upon experiencing permadeaths, and this effect was strengthened for those attached to their characters and who were lower in trait meaning making. However, there was not parallel evidence of such an effect through mortality salience. Players' mortality salience did increase their appreciation for playing - for players low meaning making players - but there was no indication that permadeath or identification with one's character impacted this relationship. Theoretical implications from these findings are discussed regarding how they contribute to the literature on character attachments and uses and gratifications, as well as how games can serve as experimental playgrounds for players. A practical implication is also presented that recommends game developers work to implement PD mechanics within their own games based on the increased replayability and appreciation PD can offer to players. 
Table of Contents

$\underline{\text { Page }}$

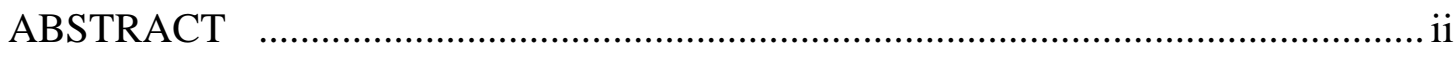

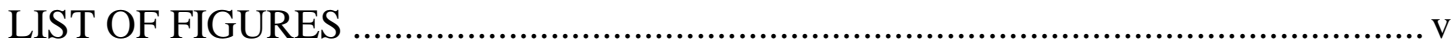

LIST OF TABLES ..................................................................................... vi

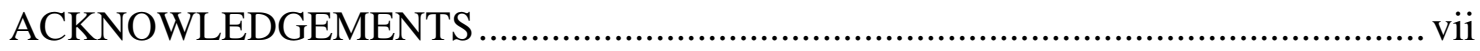

CHAPTER I: INTRODUCTION ..................................................................... 1

Second Chances and Video Game Enjoyment............................................... 3

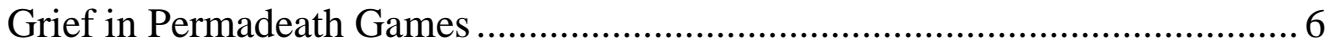

Parasocial attachment and permadeath grief................................... 7

Mortality Salience in Permadeath Games ...................................................... 10

Media and mortality salience ......................................................... 14

Identification and permadeath mortality salience ............................... 15

Permadeath as a Safe Space to Experience Meaningful Gameplay.................. 17

The eudaimonic appeal of entertainment media ................................. 18

Eudaimonic gratifications of permadeath games ................................ 22

Coping Styles and Meaning Making on Grief and Mortality Salience

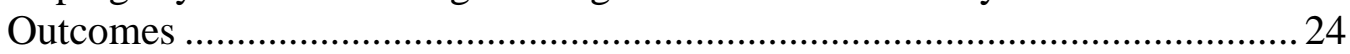

Summary and Predicted Model................................................................ 27

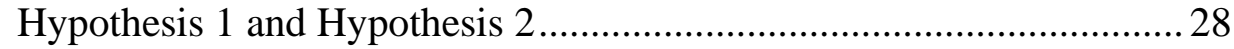

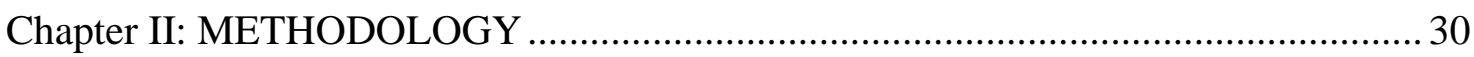

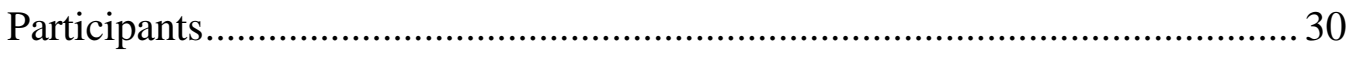

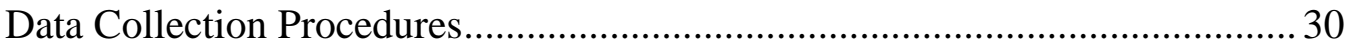

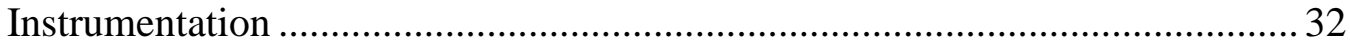

Parasocial relationship strength ................................................ 33

Identification ....................................................................... 34

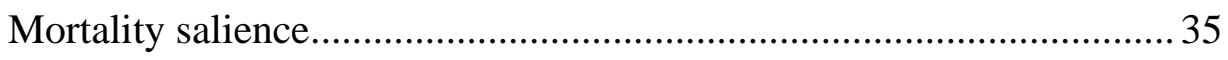

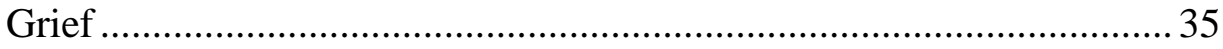

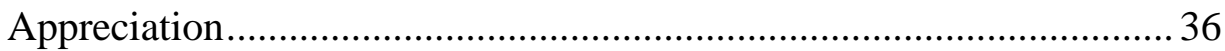

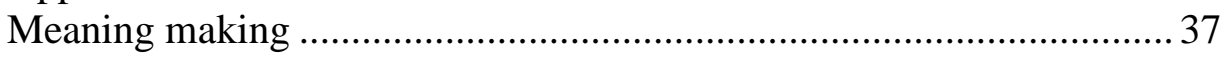

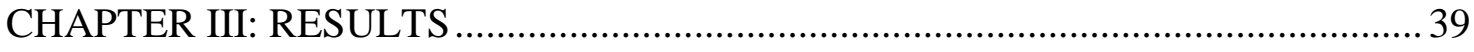

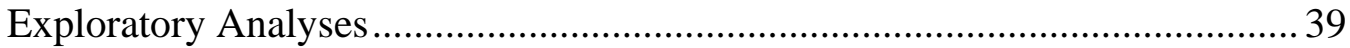

Hypothesis Tests ................................................................................ 41

Hypothesis 1 and Hypothesis 2 ................................................. 43

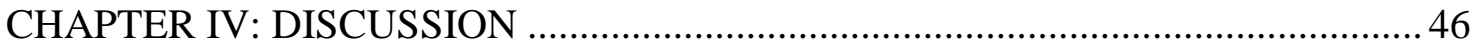

Theoretical and Practical Contributions........................................................51

Limitations and Future Directions for Research ........................................ 55 


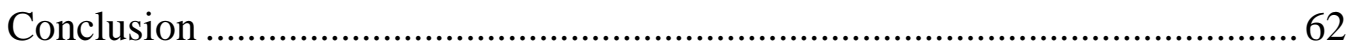

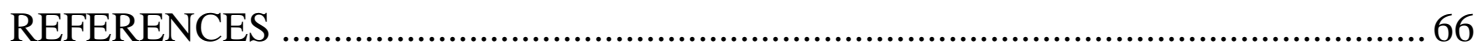

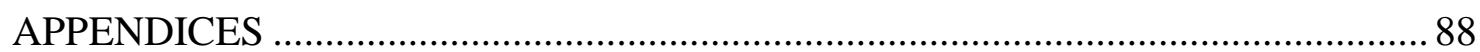

Appendix A. Reddit Recruitment Post.................................................................... 88

Appendix B. Consent information page ........................................................ 90

Appendix C. Survey Instrument …………………………………………..... 92 


\section{LIST OF FIGURES}

Page

Figure 1. $1^{\text {st }}$ Proposed Conditional Process Model.......................................................2 29

Figure 2. $2^{\text {nd }}$ Proposed Conditional Process Model ..................................................... 29 


\section{LIST OF TABLES}

$\underline{\text { Page }}$

Table 1. Correlation Residuals for Parasocial Attachment........................................ 34

Table 2. Correlation Residuals for Identification ................................................... 35

Table 3. Correlation Residuals for Grief................................................................... 38

Table 4. Correlation Residuals for Meaning Making ............................................... 38

Table 5. Summary of Descriptive Statistics and Correlations of Study Variables ........ 40

Table 6. OLS Regression Coefficients (with standard errors) from the Moderated Moderated Mediation of the Death-Appreciation Relationship through Grief............. 42

Table 7. OLS Regression Coefficients (with standard errors) from the Moderated Moderated Mediation of the Death-Appreciation Relationship through Mortality

Salience. 


\section{ACKNOWLEDGMENTS}

As I sit in my parents' family room finishing up this document, I cannot help but think back over everything that has happened since I began my journey in Morgantown, West Virginia. It. has. been. a. ride! I have met so many people who have helped me in so many ways to get to this point, and so upfront, my first order of business is to acknowledge that I cannot acknowledge everyone who has assisted me over these past few years. However, here are a few who I must absolutely mention as they have been pivotal in my growth as a person and as a scholar.

First, to all of my fellow graduate students (both doctoral and masters), I thank you for all of your love and support. As we all know, attending WVU is an experience unlike any other, and so I owe you all a deep debt of gratitude for helping to keep me smiling, motivated, and able to finish up with this degree and program. To Catie, James, and Sara, you were all wonderful mentors who helped me with every question I ever had, and while you were here, you never left a moment dull in the office. To Joe, I appreciate how you challenged everything I ever said, as you made me much better at thinking before I speak, always. To Evan, I will never forget all of the time we spent going to movies, fighting over the TV remote on conference trips, and losing "The Game” together. To Heath and Kevin, you kept my final year in the office interesting, and I will always appreciate the different perspectives on life and academia that you brought with you each day. To the Masters students (Alex, Kaitlyn, Kendall, Emma, Molly, Koji, and Carae) who helped me deal with the endless stream of student complaints and needs throughout the years, I also thank you! Alex, you also know we met the Pittsburgh Penguins...never forget! And finally, to my fellow cohort members, Stephen, Kylie, and 
Andrew: I will never be able to repay you for the countless hours of conversation and entertainment that we were able to share while we were together. I am in Le Senor's data, and he is in mine. There were times where even I felt I was married to Richard, though we were both still waiting for that frickin rock to drop. And I gained a newfound appreciation for the game of Rocket League, but I still dislike heavy metal screamo music.

Next, to all of my teachers and professors who have taught me so many wonderful things over the years, I thank you as well! I know I was a lot to deal with at times, but I do want you to know I appreciated every day you ever spent teaching and working with me to help me grow into the person I have become today. I recognize the time and devotion you all spent developing the seemingly-effortless and awesome discussions we had in class, and I know you all put way more time into reading and critiquing my work than any one person should ever have to do in a lifetime. Thank you! Thank you, thank you, thank you, thank you, THANK YOU!

To my committee members, who I have grown particularly close to over the past year, I also want to thank you for the time you spent helping me to make this dissertation the best it could be! Dr. Sharabi, you were the original person who encouraged me to cultivate my ideas on permadeath and validated my passion for the topic. Dr. Banks, my time in your classes and meeting with you in those weekly lab meetings truly helped me to refine my ideas, and your challenges have never ceased to push me to be better than I ever thought I could become. Dr. Goodboy, the countless hours and meetings we have had have truly helped me thrive in this program, and although many of those meetings involved being punks than not, I will never forget your influence in my work and in my 
life. Finally, to Dr. Cohen, I am truly grateful for your willingness to welcome me into your academic family! You were willing to move forward with me and take a step into the dark on this project despite having never really met me before, and you were willing to put yourself through double-the-workload to help me accomplish everything I ever wanted to accomplish. I promise you I have paid attention and been grateful for every sacrifice you have ever made for me over this past year, and I hope to emulate your selfless demeanor and pleasant countenance in how I work with every student as I move forward in my own career. Thank you for helping me to graduate and be able to take this next big step in my life!

To my family, I hope you know I Love you all more than anything, and I extend my deepest apologies and sincerest gratefulness for everything you have had to endure for me to get to this point in my life. Mom and Dad, you gave me everything you had and everything I ever needed to be happy and succeed. You also provided me with a good example of how to live my life and how to prepare to live me life for and with my future family of my own. To my siblings, Zach and Amanda — and to Sabrina too, I guess - you have been good brothers and sisters, and you have pushed me to strive to do my best and to offer an example that you could follow. Never forget: you must call me Dr. West now. Finally, to my hot babe of a wife, Kali, and to my beautiful daughter, Ellie, I can never repay you both for being willing to move and share your lives with me in West Virginia. You have both been the sources of my every motivation to do what I needed to do each day, and you have both been the shining lights in my life to keep me going despite every hardship I have ever faced. Now that I am finally done with this degree, I promise to do my best to be the best husband and father I can be for you both, and I will do my best to 
provide everything I can to fulfill your every need and desire forever.

Finally, I want to express my deepest gratitude to my Heavenly Father whom I know has led and guided along every step I have taken on this journey. I have done my best to glorify Him (Matthew 5: 14-16), and I can—without a doubt—say that I know I would not be where I am today without His love and compassion for me as His heavenly child. He has helped my weaknesses become strengths (Ether 12: 27), and He has ensured I was never challenged above that which I was able to bear (1 Nephi 3: 7; Alma 13: 28). All that I have accomplished here, I have accomplished for and in His name, and look forward to being in a better position to serve Him and carry out His work for the rest of my life.

Mckay Steven West April 18, 2020 


\section{CHAPTER I}

Introduction

On April 24, 2019, thousands of followers watched as Phil "Philza" Watson's character in Minecraft died after 5 years of Phil using it (Kleinman, 2019). In most cases, this event would matter to very few, and for those few, it would only matter for moments. However, being a death in a "hardcore mode" in Minecraft, this particular character death was different as it meant that Watson's character-and everything Watson had achieved with his character over those 5 years of gameplay — would be deleted forever as a consequence of this death. In other words, every bit of hard work Watson had committed with this character, every effort that he had invested in it, and every painstaking hour he had played as it were all gone-just like that.

Video game players often make great investments into the characters that they play with, sometimes devoting thousands of hours to cultivating their characters and spending time with them (see Hutchinson, 2013; Pinchefsky, 2013). As players invest this time into their characters, they experience emotional highs and lows with them, and they witness these characters maturing as their stories, their lives, progress in their games. As a result of these shared experiences with their characters, players can become attached to them (Coulson, Barnett, Ferguson, \& Gould, 2012; Lewis, Weber, \& Bowman, 2008). Sometimes, they even interact with them as if they were autonomous actors with their own lives and goals (Banks, 2015; Banks \& Bowman, 2016b). But then, similar to Watson's story above, some players can find themselves losing their characters instantaneously, without an option to bring them back.

When game characters permanently die, this game mechanic is known as 
"permadeath" (PD). Specifically, PD occurs when players' characters die an in-game death that is irrevocable, and players must then use a different character in order to continue playing the game (Copcic, McKenzie, \& Hobbs, 2013; West, Bowman, \& Cohen, 2019). The desire to play games with PD is curious given that what some may consider fun about most contemporary video games is the play-die-resurrect-repeat convention, wherein players are given multiple attempts to revive their characters and keep playing. Rather than have "second chances" to bring their characters back to life, PD game players, instead, seek out and impose (e.g., Abraham, 2013; Keogh, 2013) harsher penalties upon themselves (and by extension, their characters) while playing that essentially revoke their opportunities to have those second chances. This raises the question: what are some of the reasons that gamers voluntarily put so much more at stake while playing?

In this dissertation, I propose that a prominent motivation for playing these PD games likely stem from an enhanced sense of appreciation garnered by players through the meaningfulness of permanent character death, rather than just through simple, hedonic enjoyment. I argue appreciation arises due to PD invoking heightened reflection on the experience of the character's death, the player's death, and in general, the human condition, and that this reflection is brought about by the very grief that players experience because of their characters' deaths, as well as the potential for players to experience increased mortality salience (i.e., an awareness of one's own inevitable death). However, the extent players experience grief will be conditional upon the level of attachment (i.e., a parasocial relationship) they have for their characters, and their level of mortality salience will be conditional upon the level of players' identification with their 
characters. The extent players experience appreciation as a result of grieving for their characters and considering their own mortality will also be conditional upon how predisposed players are to make positive meaning out of negative experiences.

\section{Second Chances and Video Game Enjoyment}

Research has documented several motivations for playing video games that are typically associated with pleasure or relief. For instance, video games provide opportunities for socializing with friends or escaping into digital, fantastical realms where they can do things they otherwise would be unable to do in the real world (Sherry, Lucas, Greenberg, \& Lachlan, 2006; Yee, 2006). Like other entertainment media (e.g., Knobloch \& Zillmann, 2002; Myrick, 2015), video games also offer mood management benefits (Russoniello, O'Brien, \& Parks, 2009; Zillmann, 1988), with the ability to provide sources of arousal and/or distraction which players can use to achieve optimal, positive moods and recover from the minutia of stressors of daily life (Grodal, 2000; Jones, Scholes, Johnson, Katsikitis, \& Carras, 2014; Reinecke, 2009; Reinecke, Hartmann, \& Eden, 2014). In general, video games are associated with enjoyment (Wirth, Ryffel, von Pape, \& Karnowski, 2013; see also: Vorderer, Klimmt, \& Ritterfeld, 2004), and players even report having many of their basic psychological needs fulfilled by playing video games (Oliver et al., 2015; Przybylski, Rigby, \& Ryan, 2010; Ryan, Rigby, \& Przybylski, 2006; Tamborini, Bowman, Eden, Grizzard, \& Organ, 2010; Tamborini et al., 2011).

One reason that video game play may be associated with such positive experiences is because a key convention of most games is the provision of second chances. In most video games, decisions or missteps that players make usually do not have any permanent consequence (Klastrup, 2008; Melnic \& Melnic, 2018). 
Opportunities to reset, restart, and replay as if nothing had happened in previous attempts are a defining feature of the game play experience. For instance, in the Borderlands game series, if players accidentally sell their favorite weapons to an in-game merchant, they can buy them back with no penalty simply using the money they gained from the accidental transaction. In many of the Donkey Kong Country games, if players enter a level and discover they are not skilled enough to complete it, they have the option of changing their mind and attempting lower levels instead, at little to no cost for themselves or their characters. Generally, most games also allow players to repeatedly fight against boss levels, even when they continuously lose and their characters die.

One of the most common second chance conventions in video games is play-dieresurrect-repeat (PDRR). In most games, when players' characters effectively "die" in their game world, players usually have the opportunity to "resurrect" them and use the same character to play again. When a character dies in a PDRR game, players might lose points, some of the progress they have the made, or some other earned reward, but players will not permanently lose their character. Rather, in subsequent attempts to play the game, they typically use the same exact character that "died" in previous sessions without alteration (Klastrup, 2008). The classic game, Super Mario World, provides a good example of the PDRR cycle. When Mario dies, players can select a "Save and Continue" option in order to recommence playing with him. Players might have to restart the level from their last checkpoint, but their same character, Mario, will return, unscathed, for them to use over and over again. In this way, game characters never truly die in PDRR games.

There are a few reasons that the PDRR convention is enjoyable to players. First, it 
can provide players with a sense of control and mastery. As van den Hoogen, Poels, Ijsselsteijn, and Kort (2012) observed, avoiding death in a video game provides a sense of challenge to players while being able to resurrect their characters and try again allows them to practice and become more skilled at the game until they succeed (see also Parker, 2017; Petralito, Brühlmann, Iten, Mekler, \& Opwis, 2017). In other words, because players can take advantage of the ability to resurrect their characters to overcome challenging aspects of games and become better at playing them, players can ultimately enjoy those games more as their increased skills allow them to feel as if they are in control of the game experience (Grodal, 2000; Tamborini et al., 2010). Second, the PDRR convention lowers the stakes for players, permitting them to enjoy the challenge of the game without having to worry about any permanent, negative consequences. Having the knowledge that they can resurrect their characters, if necessary, allows players to play with the reassurance that there are few problems in the game world that cannot be fixed. This understanding may encourage players to take more risks in the game, try new experiences, and challenge themselves more (e.g., Jansz, 2005; Ryan et al., 2006). Therefore, encouraging players to be more adventurous is another way PDRR games may lead to enjoyment.

Considering that PDRR is likely part of the formula for video game enjoyment, the rise in popularity of PD games is intriguing (see Chang, Costantino, \& Soderman, 2017). If the reversibility of characters' deaths offered by the PDRR cycle helps players to enjoy video games, why would players purposefully choose to play games with irrevocable consequences for their characters' lives, such as in PD games? As the following sections of this manuscript will explain, PD games likely invoke negative, 
emotionally taxing experiences for players as they lose their characters, but under the right conditions, they may also find these experiences to be meaningful as well.

\section{Grief in Permadeath Games}

Accounts of PD experiences suggest that they can be harrowing for players. In discussing the ways PD game developers handle death in their games, developer Garry Newman stated, "We treat the player like shit [in PD games]. They're not used to that" (Griffin, 2014, para. 8). Bartle (2004) similarly described the PD experience for characters as them being "consigned to oblivion" (p. 416) because they cease to exist upon dying. Jake Solomon, a game designer, similarly explained that "permanent death brings real consequences to the games we play...It evokes dread and a real sense of loss in players, because it's something that they don't want and they can't undo once it has happened" (Groen, 2012, para. 6).

Despite the fictional nature of PD, these losses can have very real emotional consequences for players (Harrer, 2013), somewhat resembling grief experienced for those in our real-world social networks. Grief can be defined as the "clusters of cognitive, emotional, somatic, and behavioral symptoms" (Tomita \& Kitamura, 2002, p. 95) that people may experience, both initially and even after extended periods of time, upon losing someone or something important to themselves. Various studies have demonstrated that audiences can experience pronounced grief and distress in response to the deaths of media characters, celebrities, and public figures (Cohen, 2003; Cohen \& Hoffner, 2016; Daniel \& Westerman, 2017; DeGroot \& Leith, 2015; Eyal \& Cohen, 2006; Sanderson \& Cheong, 2010). As with the death of people within one's social network, mourners of media figures report expressing similar feelings, such as sadness, 
surprise, longing, confusion, and love (DeGroot \& Leith, 2015). They also engage in many customary mourning processes and rituals (e.g., giving online eulogies; Holiman, 2013), and in studies of both fictional characters and celebrity deaths, media figure mourners appear to experience each of Kübler-Ross' (1969) five stages of grief in a similar manner as they would for their real social contacts too (Daniel \& Westerman, 2017; Sanderson \& Cheong, 2010). People who mourn media figures also appear to engage in the same types of strategies to cope with their emotions as people mourning for people in their social networks (e.g., Cohen \& Hoffner, 2016), such as memorializing the deceased by paying their respects and connecting with other mourners on social media (e.g., Sanderson \& Cheong, 2010 ), donating to charities (e.g., Brown, 2010), consuming media related to the deceased (e.g., Brown, Basil, \& Bocarnea, 2003), and/or purchasing paraphernalia related to the deceased (Radford \& Bloch, 2012). In the video game, Second Life, it is not uncommon for players to even create digital cemetery plots in order to memorialize not only friends and family who they have lost, but also their characters lost in-game as well (Gibson, 2017).

Parasocial attachment and permadeath grief. The stress of anticipating or grieving after experiencing PD should be particularly pronounced for players who have developed feelings of relational attachment for their characters. In their seminal article, Horton and Wohl (1956) observed people's tendency to develop “one-sided, nondialectical" relationships (p. 215) with media figures, characterized by an "illusion of intimacy" (p. 217), or a sense of closeness to the media figures they come to know through their media usage. These parasocial relationships (PSRs) are emotional bonds that people feel toward media figures that often exist even beyond direct exposure to the 
figures in the media (Dibble, Hartmann, \& Rosaen, 2016). In other words, they may find themselves thinking about that figure long after reading about or having seen them. Though Horton and Wohl originally observed the development of PSRs with radio and TV personalities (see also Horton \& Strauss, 1957), researchers have since observed people can develop PSRs with a variety of media figure types, including fictional characters (Daniel \& Westerman, 2017; DeGroot \& Leith, 2015; Rosaen \& Dibble, 2008), animated characters (Jennings \& Alper, 2016; Rosaen \& Dibble, 2008), and celebrities (Kim \& Song, 2016).

Video game characters can also foster strong feelings of closeness and attachment from players (Banks, 2015; Lewis et al., 2008; Song \& Fox, 2016). In fact, because they afford players the opportunity to create, take care of, and "interact with" their characters, video games may be able to forge particularly strong player-character bonds. The Investment Model (e.g., Rusbult, 1980; Rusbult, Agnew, \& Arriaga, 2012) contends that people tend to feel more dependent on and committed to social relationships in which they have more invested in terms of time and energy, shared experiences, and shared friends and possessions. The same investment process may explain how video game players come to feel committed to their characters. Though some players may view their characters as nothing more than objects on a screen — tools to accomplish their objectives in the game (Banks, 2015; Banks \& Bowman, 2013)—others can come to feel intimately attached to their game characters as they invest a great deal of time and energy in developing their characters, in helping them to "level up" and acquire new skills to increase their chances of survival, and in guiding them through their game worlds. Some have argued that players even engage in something akin to two-sided communication 
with their characters when using controller/keyboard inputs (Banks, 2015; Lewis et al., 2008). Perhaps not surprisingly, the more that players feel they have a relationship with their characters, the greater they also feel a sense of responsibility for those characters' well-being (Banks \& Bowman, 2016a, 2016b). These player investments in their game characters should breed an increased sense of closeness, commitment, and parasocial attachment.

Importantly, research has also demonstrated that stronger parasocial bonds with media figures are associated with more intense experiences of grief upon the death or abrupt dissolution of the illusionary relationships (Cohen, 2003; Cohen \& Hoffner, 2016; Eyal \& Cohen, 2006). For example, Cohen and Hoffner (2016) found that fans of Robin Williams who felt more parasocially attached to the actor expressed greater amounts of grief in response to his passing. This positive relationship between parasocial attachment and grief was also observed in a sample of viewers responding to the series finale of the popular sitcom, Friends (Eyal \& Cohen, 2006), with viewers indicating increased distress at the thought of losing their various forms of media figures. Notably, in these studies the relationship between parasocial attachment and grief also tended to be rather high $(r=.58$ to .81 ), indicating that the link between parasocial bonding and grief is fairly strong.

Given the aforementioned research, it seems that players of PD games should be more susceptible to experiencing grief after the loss of a character, compared to players of PDRR games because this loss is permanent. This grief is likely to be conditional on parasocial attachment. Because PSR intensifies the grief experience (e.g., Cohen \& Hoffner, 2016), the more attached players feel to their characters, the stronger their grief should be upon losing their characters. Stated, differently, compared to character deaths 
in PDRR games, PDs will result in more intense grief for players, and this effect will be moderated by the intensity of players' PSR, such that players who are more attached to their characters will experience increased levels of grief in response to their deaths.

\section{Mortality Salience in Permadeath Games}

Beyond experiencing increased grief resulting from their characters' PDs, those deaths may also increase players' mortality salience (MS), or in other words, the contemplation of their own mortality or the fact that they too will inevitably die. Terror Management Theory (TMT; Greenberg, Pyszczynski, \& Solomon, 1986; Solomon, Greenberg, \& Pyszczynski, 1991) contends that all anxieties stem from an over-arching fear of dying. People fear death because it may lead to the "absolute annihilation" (p. 101) of their being, as they may never think, feel, or simply be again. People also fear death because it is one aspect of their existence that they cannot control (excluding premature actions to euthanize themselves; see Pihlström, 2015), and with death usually come grief, depression, and other undesirable outcomes to those involved with the deceased (Kübler-Ross, 1969; Meij et al., 2005). In other words, people fear the possibility that they may one day cease to exist and that there is nothing they can do about it. They fear their death will cause themselves to become a burden to their loved ones (Kehl, 2006; Meier et al., 2016; Williams-Murphy, 2012). They also fear the thought of losing those loved ones forever, not only because they know it will bring emotional hardships to their own lives (e.g., Kübler-Ross, 1969; Meij et al., 2005), but because the thought of others dying also reminds people that they too can die (Greenberg, Pyszczynski, Solomon, Simon, \& Breus, 1994). Kelly (2012) even argued that America's fear of death has progressed to such a point that people wish to "sanitize" even the very 
mention of death in their homes, workplaces, and hospitals, simply because they do not want to increase their own MS.

Importantly, a key tenet of TMT is that people fear death most when their MS increases (Greenberg et al., 1986, Solomon et al., 1991). Furthermore, as their MS increases, so does their anxiety to an extent that they may simply become unable to function, physically or psychologically (Greenberg et al., 1986, Solomon et al., 1991), even risking damage to their psychological well-being (Juhl \& Routledge, 2016) by feeling less satisfied with life and having lower overall subjective vitality (i.e., feeling less alive and energized; Routledge et al., 2010). In order to cope with MS, TMT posits people surround themselves in "cultural anxiety [buffers]...to assuage the terror" (Solomon et al., 1991, p. 97) so they can better function in daily life. These buffers, often derived from various societal groups (e.g., religious associations) or individual predispositions (e.g., having a tendency to laugh to cope; see Wanzer, Booth-Butterfield, \& Booth-Butterfield, 2005), involve people subscribing to cultural worldviews, principles, or ideas that (1) give their lives meaning and significance, (2) provide standards by which their behaviors can be assessed/assigned value, and (3) offer hope of literal/symbolic immortality if they are willing to live in accordance with those standards (Pyszczynski, Solomon, \& Greenberg, 2015). In other words, to quell their MS, people derive a set of rules, principles, and practices that they believe can give purpose to their lives, and by successfully abiding by those rules, principles, and practices, they believe their existence will persist literally (i.e., through some form of afterlife) or symbolically (through their legacies passed down by surviving family and community members).

Researchers have found that people's cultural anxiety buffers function differently 
depending on the extent they are consciously processing their MS. For instance, Greenberg et al. (1994) first observed that whether participants were exposed to some form of distraction or delay (e.g., a puzzle task) impacted the relationship between MS and how people evaluated others, such that people rated in-group members who subscribed to their own worldviews more highly than out-group members, but only when there was a delay between the death stimulus and participants' rating others. Since then, researchers have observed that there are generally two routes of defensive processing against MS that people generally undergo — proximal or distal—and each route ultimately affects how well people's cultural anxiety buffers serve to psychologically defend themselves. Proximal defense processing occurs when people are conscious of their MS, and therefore, attempt to resolve their death-related thoughts directly. Distal defense processing, however, occurs when people unconsciously process their MS, and so when they attempt to resolve their death-related thoughts, they do so symbolically through defending their own cultural worldviews, boosting their self-esteem, or becoming closely attached to others (Greenberg et al., 1994). For instance, Routledge, Arndt, and Goldenberg (2004) found that when people were asked to rate the likelihood they would buy different sunscreens of various SPF levels, those responding immediately after completing a death-related thought measure used to invoke MS (i.e., those proximally processing their death-related thoughts) indicated they would be more likely to use sunscreen to prevent their deaths. However, when people were first given a distractor task and were able to forget about the deadly effects of not using sunscreen (i.e., distally processing their death-related thoughts), they indicated being less likely to use sunscreen, especially after receiving reinforcement that tan skin is attractive. Routledge et al. argued 
these findings offered support for proximal/distal processing as people who proximally processed the message directly attempted to resolve their MS while those who distally processed the message were more concerned with symbolically resolving their MS by making a decision that would aid them in upholding their cultural worldviews (i.e., being attractive). Thus, from the above research, it can be discerned that people are adversely affected by their fears of dying, but that they have also developed various mechanisms through establishing cultural anxiety buffers that help themselves cope with their fears. When people consciously experience death-related thoughts and their MS is increased, they first attempt to resolve those thoughts proximally, and later, their inner psyche must resolve those thoughts distally.

Previous work on TMT has largely focused on how MS, anxiety, and cultural worldviews relate to each other (Pyszczynski et al., 2015; see also Rieger, 2017), and this research can generally be explained via two formal hypotheses: the (1) mortality salience and (2) anxiety buffer hypotheses. These hypotheses are not considered competing hypotheses, but rather, each focuses on a different time frame for when people must confront MS. First, the MS hypothesis predicts that when people are faced with deathrelated thoughts, their need and commitment to their cultural worldviews are increased and their tolerance and support of opposing worldviews is decreased. For instance, under high MS, people have been observed to give more positive evaluations of in-group members and be more likely to praise them (Greenberg et al., 1990; Greenberg et al., 1994), hold greater attitudes toward homeland political leaders following acts of terrorism (Landau et al., 2004), and to assign harsher punishments to out-group members - especially those who committed a moral violation (Rosenblatt, Greenberg, 
Solomon, Pyszczynski, \& Lyon, 1989). A meta-analysis examining 277 different MS experiments (see Burke, Martens, \& Faucher, 2009) found a positive relationship ( $r=$ .35) between death-related thoughts and increased worldview bolstering and defense, providing robust support for this hypothesis.

The anxiety buffer hypothesis, on the other hand, predicts that the greater cultural anxiety buffers people have in place, the less likely they are to experience anxiety when confronted with MS or death-related thoughts (Pyszczynski et al., 2015). In other words, whereas the MS hypothesis pertains to reactive defense processing, the anxiety buffer hypothesis pertains to proactive defense processing, as people's preemptive construction of their cultural anxiety buffers essentially serves to reduce the negative impacts of confronting death-related thoughts. For example, Juhl and Routledge (2016) outlined a series of studies in which they found that people confronted by MS experienced increased anxiety and lower well-being, but only when they found little meaning in life, were not nostalgic for previous meaningful events, did not perceive themselves to belong to important social groups, or had low self-worth. Conversely, people who found meaning in life and were highly nostalgic, had high interdependent self-construals, and possessed high self-worth were not impacted by MS. Thus, Juhl and Routledge's work largely supports the anxiety buffer hypothesis as it seems those who are most protected from the negative impact of MS are those who already have an effective cultural anxiety buffer in place to shield themselves. Altogether, this notion of having a pre-established cultural anxiety buffer can ultimately help explain why some people are more comfortable than others at consuming unpleasant media content.

Media and mortality salience. Media commonly portray death in a variety of 
ways that might invoke MS in users, and researchers have recently begun examining this relationship between media-usage and user MS. For instance, Arndt, Greenberg, Pyszczynski, and Solomon (1997) found that they could experimentally increase people's MS by simply flashing the word "death" on screen, indicating MS could easily be heightened in people using media via subliminal forms of messaging. MS has also been experimentally manipulated via slide show (Hong, Wong, \& Liu, 2001), car accident commercial (Nelson, Moore, Olivetti, \& Scott, 1997), and watching a film on the Holocaust (Kumagai \& Ohbuchi, 2003). Burke et al.’s (2009) meta-analysis findings indicated there were no significant differences between these manipulations and their impact on MS; each experimental manipulation successfully increased MS in users to some extent. In an unpublished manuscript, Tsay, Krakowiak, and Oliver (2012) also found that media content increased viewers' MS. Specifically, these researchers found that sad and tender films increased viewers' sad affect, and in turn, this increased the number of death-related thoughts those viewers had. Altogether then, this culmination of research offers a foundation for MS-media research that suggests MS can be invoked through media, particularly sad media content that often contains themes of death and loss.

Identification and permadeath mortality salience. Because past research indicates other media have the potential to invoke MS in users (Arndt et al., 1997; Hofer, 2013; Hong et al., 2001; Kumagai \& Ohbuchi, 2003; Nelson et al., 1997; Rieger et al., 2015; Rieger \& Hofer, 2017; Tsay et al., 2012), it is not unfounded to assume video games have the same potential. In fact, in her Masters thesis, Anderson (2015) even argued this very relationship exits. Accordingly, a variable that has the potential to help 
explain why some games may elicit more MS than others is players' identification with their game characters.

Identification has been defined by prominent scholars as replacing one's "role as audience member with the identity and role of the character within the text" (Cohen, 2001, p. 251) and as, "the experiential merger of a media user (e.g., a reader) and a media character" (Klimmt, Hefner, Vorderer, Roth, \& Blake, 2010; p. 324). Identification occurs when players literally adopt the cognitions and emotions of their video game characters. Stated another way, identification consists of those fleeting moments when people perceive themselves to $b e$ their media figures, to empathize and feel how that figure feels, and to think as if that figure's thoughts (i.e., its ideas, plans, and goals) were their own. Because video games are interactive and permit players to manipulate the actions of their game characters-essentially permitting them to step into their characters' shoes, so to speak - this form of media is uniquely well-suited to facilitate players' identification with their characters (Klimmt, Hefner, \& Vorderer, 2009; Klimmt et al., 2010). Previous work by Banks (2015; see also Banks \& Bowman, 2016a, 2016b) provides support for this argument as Banks and colleagues have found that player identification with their characters can occur, especially for players low in selfdifferentiation (i.e., having the tendency to see their characters as "others"; Banks, 2015) and who play for social purposes.

There is reason to suspect that character identification may determine the extent that players' MS is increased after the death of a character. After all, MS is contingent upon people's perceptions that they, themselves, actually have the ability to die, and through identification, players temporarily merge their "selves" with their characters. 
Some research has established that just the thought of another's death is enough to increase a person's MS. Specifically, Greenberg et al. (1994) found that people's MS increased when simply thinking of losing a loved one. However, this effect was much smaller than when participants were asked to consider their own deaths, indicating that self-related death-thoughts seem to exert a more powerful influence on MS than otherrelated death-thoughts. Accordingly, while the permanence of character deaths in PD games creates ripe conditions for cultivating players' MS, the more players identify with their characters, the more salient their own mortality should also become. After all, the more they see themselves as their characters, when those characters die, the more likely it should seem as if they have lost a part of themselves. For this reason, identifying with the characters by adopting their cognitive and emotional perspectives should increase the salience of players' own deaths when their characters die.

\section{Permadeath as a Safe Space to Experience Meaningful Gameplay}

Thus far, this manuscript has argued that compared to character deaths in PDRR games, character deaths in PD games should evoke more grief and more MS. The more players' feel parasocially attached to their characters, the more they should grieve the loss of those characters. Similarly, the more players identify with their characters, the more salient should their own mortalities become. Altogether then, it is interesting that players would seek out PD experiences, as by most theoretical accounts, both grief and MS are typically unpleasant outcomes (Kübler-Ross, 1969; Solomon et al., 1991; Tomita \& Kitamura, 2002). Furthermore, people generally play video games for similar purposes as they do other media—-for enjoyment (Vorderer et al., 2004; Wirth et al., 2013), to improve their mood (Russoniello et al., 2009; Zillmann, 1988; see also, Reinecke, 2017), 
and to recover from daily stressors (Grodal, 2000; Jones et al., 2014; Reinecke, 2009;

Reinecke et al., 2014) — and so it is rather paradoxical that players would actively choose to play PD games given their content is likely to hinder such positive outcomes rather than promote them. It could be that players are motivated to play PD games due to some form of perceptions of increased challenge that the games might offer (e.g., Sherry et al., 2006; Yee, 2006). However, another explanation for why players choose to play PD games may be that they are, instead, drawn to some form of eudaimonic gratifications gained from playing these games rather than their hedonic rewards (Vorderer \& Reinecke, 2015).

\section{The eudaimonic appeal of entertainment media}

Eudaimonia refers to the state of feeling purposeful, fulfilled, and meaningful (Oliver \& Bartsch, 2010). Like hedonism, eudaimonia is considered a form of happiness (Waterman, 1993). However, while hedonism is rooted in comfort and pleasure (i.e., an absence of pain), eudaimonia is happiness that stems from cognitive reflection (Oliver \& Bartsch, 2010), a sense of personal growth (Schutter \& Brown, 2015), and finding knowledge, purpose, or meaning (Bowman et al., 2016; Oliver \& Bartsch, 2010, 2011; Oliver \& Raney, 2011; Oliver et al., 2015; see also Lewis, Tamborini, \& Weber, 2014). As Oliver (2008) describes it, eudaimonia is when people derive happiness from their contemplation of life's meaning and human poignancies (e.g., what makes life valuable). Thus, while hedonism generally involves people feeling positive emotions such as excitement, eudaimonia is often associated with what Oliver (2008) has termed "tender affective states" wherein people feel emotions such as tenderness, compassion, empathy, elevation, hope, and even a sublime sense of awe (Oliver, 2008; Oliver et al., 2018; see 
also Raney, Oliver, \& Bartsch, 2019; Slater, Oliver, \& Appel, 2016). People also respond cognitively to eudaimonic experiences by engaging in processes such as meaning making, emotional reappraisal, elaboration, and contemplation (Oliver \& Bartsch, 2010, 2011; see also Raney et al., 2019). As such, hedonic experiences have typically been characterized as people "enjoying” something while eudaimonic experiences are characterized as them "appreciating” it. However, as Raney et al. (2019) state, it is important to recognize that hedonism and eudaimonia should not be "conceptualized as mutually exclusive or as opposite ends of a continuum, but rather as [being] orthogonal" (p. 259). People are capable of both enjoying and appreciating events, such as how parents might feel upon watching their child leave for college (i.e., excited to see them move on, sad to see them leave). Likewise, both types of experiences can ultimately fulfill people's basic psychological needs (Carras et al., 2018; Rigby \& Ryan, 2016), though they just tend to do so in different ways (e.g., Tamborini et al., 2010; Tamborini et al., 2011). Eudaimonia, then, is a process wherein people often experience a series of different emotions and cognitions which may not be inherently enjoyable, but through the entirety of the experience, can help them generate meaning and understanding regarding life's meaning and the world around themselves.

Raney et al. (2019) pointed out that early media entertainment research tended to focus heavily on the hedonic uses and gratifications of media. For instance, classic Mood Management Theory (Zillmann, 1988) is premised on the assumption that people are drawn to media as a means of optimizing their affective experience. However, more recent research has shown that not only do people seek out non-hedonic media in order to create or maintain negative as well as positive moods (Knobloch-Westerwick \& Alter, 
2006), but studies have also demonstrated that people are often motivated to seek out and consume counter-hedonic entertainment media in order to derive eudaimonic gratifications (Oliver \& Bartsch, 2010; Oliver \& Raney, 2011). Over the past couple of decades, a great deal of empirical research has accumulated on how certain types of media content can lead to eudaimonic or meaningful experiences for audiences (e.g., Bartsch, Kalch, \& Oliver, 2014; Goldenberg, Pyszczynski, Johnson, Greenberg, \& Solomon, 1999; Grodal, 2007; Klimmt, 2011; Knobloch-Westerwick, Gong, Hagner, \& Kerbeykian, 2012; Oliver, 2008; Oliver \& Bartsch, 2010; Oliver \& Hartmann, 2010; Perloff, 2016; Wirth, Hofer, \& Schramm, 2012). For instance, by experimentally manipulating whether a film retained its original dramatic music, Bartsch et al. (2014) found students in the music-inclusive film condition rated the film as inducing more mixed affect, and they reported "feeling moved" more by the film; in turn, those emotions also increased students' reflective thinking on a self-report measure and thought-listing exercise. Similarly, using student responses to different types of films (serious, light, action), Oliver and Bartsch (2010) also found students reported the greatest amount of appreciation for serious films (i.e., sad or dramatic films such as To Kill a Mockingbird and Life is Beautiful), as they found those films to be both moving and thought-provoking. Interestingly, users often report that sad, dramatic, tender, and tragic media tend to invoke more meaningful experiences (Goldenberg et al., 1999; Oliver, 1993; 2008; Oliver \& Hartmann, 2010; Wirth, Hofer, \& Schramm, 2012). Raney et al. (2019) argued that these types of films are particularly adept at increasing viewer appreciation because they promote reflection on life's meaning and the human condition (see also, Koopman, 2015). However, Raney et al. also pointed out that "even the most 
light-hearted fare [can include] meaningful content — such as depictions of love, hope, or kindness" (p. 260) because those media, too, can cause people to reflect on the world around themselves.

Although most research on meaningful media has focused on film and television, a few recent studies have also examined characteristics of video games that lead to meaningful playing experiences. For instance, Oliver et al. (2015) observed that most players were able to identify not only a "fun" game that they had played, but also one that was "meaningful" to them. They found that players reported having more appreciation and gaining more insight from games they perceived to have higher quality narratives, whereas they reported increased enjoyment from games they perceived as having higher quality gameplay mechanics. In other words, people were more likely to have meaningful experiences when focusing on more complex elements of video games that might encourage cognitive reflection (e.g., depth of character development, quality of plot development), whereas they were more likely to base assessments of enjoyment on considerations of how the game functioned (e.g., ease of control, quality of reward systems). In the same vein of research, Bowman et al. (2016) found that players who had an increased sense of identification with their characters and who felt greater responsibility for their characters had increased appreciation for the games they were playing. In other words, by players feeling as if they were their characters and that their in-game actions had a direct impact on their characters' well-being, players appreciated their gameplay experiences more. Altogether, these findings indicate that, similar to other forms of media, video games can offer emotionally complex experiences to players that can encourage self-reflection and help players to derive meaning from the overall play 
experience. In doing so, it is possible that such experiences can serve as a key

eudaimonic gratification for players that would motivate them to play PD games.

Eudaimonic gratifications of permadeath games. Collectively, the research on eudaimonic gratifications of entertainment media suggests that the appeal of PD games may be rooted in their ability to provide meaningful experiences for players. There are a number of reasons to think that the PD experience could be meaningful. One reason is that PD games provide relatively more realistic gameplay experiences than PDRR games. As Groen (2012) exclaimed, 'it's hard to call a war game 'realistic' when the soldiers magically resurrect after being shot in the head" (para. 4). However, "true" character deaths are imbued with more meaning because they are tragically irreversible, much like the deaths of real people. The high stakes nature of PD games - where at any moment a character could be irrevocably lost (e.g., Keogh, 2013) — may also make playing these games more meaningful. In a mixed method study, Carter and Allison (2017) examined player responses to PD in the game DayZ (see also Allison, Carter, \& Gibbs, 2015). Analysis of responses from 1,704 participants in 64 different countries, revealed that players found PD to be extremely frustrating; however, they also indicated that the everlooming threat of PD gave more meaning to the lives of their characters, and they reported the constant threat of permanently losing their characters made their in-game decisions matter more. These reports echo Rousse's (2011) contention that in PD games, characters are inherently more valuable, unique, and irreplaceable to players because they are constantly at risk of being irrevocably lost forever. Because PD games make the consequences of character death more socially real (i.e., "true to life"; Lombard \& Ditton, 1997) in the sense that characters can suffer a true (i.e., permanent) death, this can even 
have the effect of infusing those characters' lives with more meaning and making them seem more "alive" since they only have one life to live (Lynch \& Matthews, 2017), and thereby, all of their actions may just be their last.

This seeming "aliveness" is likely only amplified by the fact that PD games are often created in tandem with procedural generation mechanics, wherein content (e.g., characters, enemies, and settings) is continually created and recreated as players begin each new game or level and encounter each new character or enemy. In procedurallygenerated PD games, every computer-created character players take control of is often made to look, sound, and/or behave differently from other created characters while also possessing different names, backstories, and/or abilities. These unique characters also go on personalized adventures where they encounter uniquely crafted areas with different amalgamations of enemies, events, and treasure rewards. Because they have entirely different experiences in procedurally-generated PD games, two characters are never fully alike, and in this way, they simulate the uniqueness of people in the real world. Because players can never use their exact characters again once they die in a procedurallygenerated PD game, players may have a heightened perception that their characters are significant, irreplaceable, and alive (Parker, 2017; Rousse, 2011; White \& Grossfeld, 2012). Therefore, because players are in charge of handling the welfare of their characters, they may find their experiences with these characters to be more meaningful as they are now ultimately responsible for their "lives" (e.g., Bowman et al., 2016) lives that they likely care about, have invested in, and hope to sustain.

In sum, PDs have the potential to offer more meaningful gameplay experiences than temporary deaths in PDRR games. While players are still able to experience many of 
the enjoyable perks of video game play in PD games that likely induce positive affect (e.g., challenge, socializing; Sherry et al., 2006; Yee, 2006), the loss of their characters can introduce negative affective and cognitive experiences that can dampen the type of enjoyment that players might expect from a typical PDRR game. This makes selective exposure to PD games seem curious unless, rather than simply seeking a hedonic gameplay experience, players are actually seeking a more meaningful, eudaimonic experience. The realism of PDs and the deep sense of connection that players can forge with characters who are mortal, like human beings, should make the experience of playing these games more meaningful. For this reason, compared to PDRR deaths, players should be naturally more inclined to appreciate PDs. However, this appreciation should occur via an indirect effect through negative affective experiences like grief and increased MS. Specifically, in the event of a PD, players should experience grief and increased MS which, in turn, should then enhance the sense of appreciation players feel because the experience (although less pleasant) would be more meaningful. However, not every player will be able to appreciate these affectively challenging experiences. I expect only players who have a tendency to cope with adverse experiences by extracting meaning from them may appreciate the difficult affective experiences that arise from PD.

\section{Coping Styles and Meaning Making on Grief and Mortality Salience Outcomes}

Coping refers to when people consciously or unconsciously invest their "efforts to prevent or diminish threat, harm, and loss, or to reduce associated stress" (Carver \& Connor-Smith, 2010, p. 685). According to Carver and Connor-Smith, coping can generally be conceptualized as either problem-focused (i.e., acting to remove the stressor, itself) or emotion-focused (i.e., acting to reduce stress brought on by stressors), and 
people can choose to directly engage their stressors or actively avoid them. People who directly confront stressors can also engage in meaning-focused coping, wherein they draw on their beliefs, values, and existential goals to (1) find benefits, (2) remind themselves of benefits, (3) set achievable goals, (4) reorder their priorities (5) or infuse events with positive meaning, all to motivate and help sustain their coping efforts during difficult times (Carver \& Connor-Smith, 2010; Folkman, 1997, 2008). One form of meaning-focused coping that is particularly pertinent to this study is meaning making (Park, 2010).

Meaning making (MM) refers to when people attempt to "make sense of, assign meaning to, and address stressful life events" (Carmack \& LeFebvre, 2019, p. 351) to reduce discrepancies between what something is and what they believe it should be (Park, 2010). In other words, when people cope via MM, they do so by reappraising negative events and focusing on potentially positive meanings that might be gleaned from them, and doing this ultimately aids them in dealing with their stressors. As such, MM is an emotion-focused form of coping rather than problem-focused (see Carver, Scheier, \& Weintraub, 1989), and so it is particularly suited for studying how people might handle grief and death. People cannot change or fix death after it happens - they can only cope with it. However, in line with the anxiety buffer hypothesis (see Pyszczynski et al., 2015; Rieger, 2017), though people cannot prevent death, they can proactively prepare themselves to cope with death-related thoughts and any anxieties that might arise from them. Thus, it might be argued that a large portion of developing an effective cultural anxiety buffer is simply learning to adapt one's worldviews of death to be able to cope with it (e.g., being able to make meaning out of death once it happens), and therefore, 
examining people's predispositions to make positive meaning out of negative events, particularly death, could serve as a way to measure the effectiveness of their preestablished cultural anxiety buffers.

Putting all of this together, I have argued that PD should be an inherently negative experience because it evokes grief and raises MS (Kübler-Ross, 1969; Solomon et al., 1991; Tomita \& Kitamura, 2002). While these experiences could lead to a more meaningful experience for some players, this seems contingent on those players having an ability to cope successfully. Specifically, while players who are more inclined to make meaning out of stressful experiences might be able to appreciate the PD experience, players with lower predispositions for MM should be less likely to extract that meaning from their grief and MS (Juhl \& Routledge, 2016). Indeed, for players with higher predispositions for MM, PD games may provide a space to safely experiment with the grief and MS that PD games evoke. These players' trait MM would aid them in appreciating the unpleasantness of grief and MS because they would be particularly inclined to cope with their negative affect through MM by finding greater purpose in their negative game experiences, therefore enabling them to appreciate the experience more and learn from it. There is some precedent for this in a study of responses to the dramatic film, Life Without Me (a story of a mother diagnosed with cancer who must still care for her children). Hofer (2013) found that people's MS increased their appreciation of the dramatic film, but only for those people who were more prone to seek out meaning in life. Extending this finding, the positive effect of both grief and MS on game appreciation should be conditional on players' predispositions for MM, such that the positive effect of grief and MS will be increased the higher players are in trait MM. 


\section{Summary and Predicted Model}

The rise in popularity of PD is interesting because, unlike more traditional and common PDRR games, PD games are characterized by more intense negative affective experiences, and importantly, they do not provide players with second chances to reuse characters that have succumbed to the game's challenges. One consequence of the irrevocable nature of these PD games is that players should experience greater grief in the event of a character death. Another consequence of PD games is that players should experience increased MS due to constant reminders of their game characters' mortality. Media have been demonstrated to be effective tools for invoking MS in people (Arndt et al., 1997; Hofer, 2013; Hong et al., 2001; Kumagai \& Ohbuchi, 2003; Nelson et al., 1997; Rieger et al., 2015; Rieger \& Hofer, 2017; Tsay et al., 2012), and so the interactive environments of PD games and the permanent deaths of players' characters should be particularly powerful in causing players to ponder their own mortality.

The effects of PD on grief and MS should be particularly pronounced for players who have intense attachments with their game characters. A stronger sense of parasocial attachment to one's character - a sense that the character is a relationally close othershould increase players' grief after their loss (e.g., Hoffner \& Cohen, 2016). On the other hand, a stronger sense of identification with one's character-a sense that the character is a part of oneself - should increase players' personal MS, or an awareness of the fragility of their own lives. Put differently, the effects of PD on grief and MS should be conditional on parasocial attachment and identification, respectively. However, although unpleasant, these experiences of grief and MS may ultimately explain why some people voluntarily play emotionally taxing games that have PD mechanics. These PD 
experiences could make the game experience more meaningful. PD offers players a realistic experience and a safe space to grapple with complex thoughts and emotions. In this way, the increased grief and MS experienced in response to a PD should enhance players' appreciation. Nonetheless, only players who are predisposed to seek meaning in negative experiences (in this case, grief and MS), should be able to appreciate PD experiences (see Carver et al., 1989; Pyszczynski et al., 2015; Rieger, 2017). Players with predispositions for positive MM are expected to have greater appreciation for PD games, as they should be more effective in reappraising their grief and MS from the loss of their characters to ultimately find greater meaning from the entirety of the gameplay experience. In other words, the effects of PD on appreciation through grief and MS should be conditional on players' trait MM.

Based on this logic, the following two hypotheses were proposed. The complete predicted models are illustrated in Figure 1 and Figure 2.

H1: The indirect effect of permadeath on appreciation through grief, will be conditional on both parasocial attachment and meaning making. The indirect effect of permadeath on appreciation will be greater the more players felt parasocially attached to the character, and the more predisposed they are to meaning making.

H2: The indirect effect of permadeath on appreciation through mortality salience, will be conditional on both identification and meaning making. The indirect effect of permadeath on appreciation will be greater the more players identified with the character, and the more predisposed they are to meaning making. 
Figure 1. $1^{\text {st }}$ Proposed Conditional Process Model

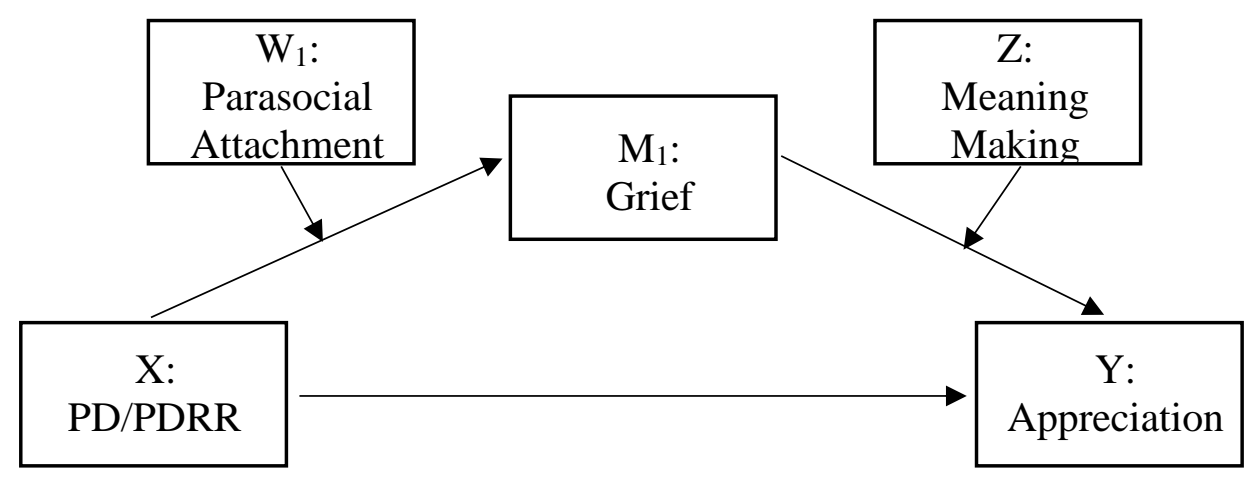

Figure 2. $2^{\text {nd }}$ Proposed Conditional Process Model

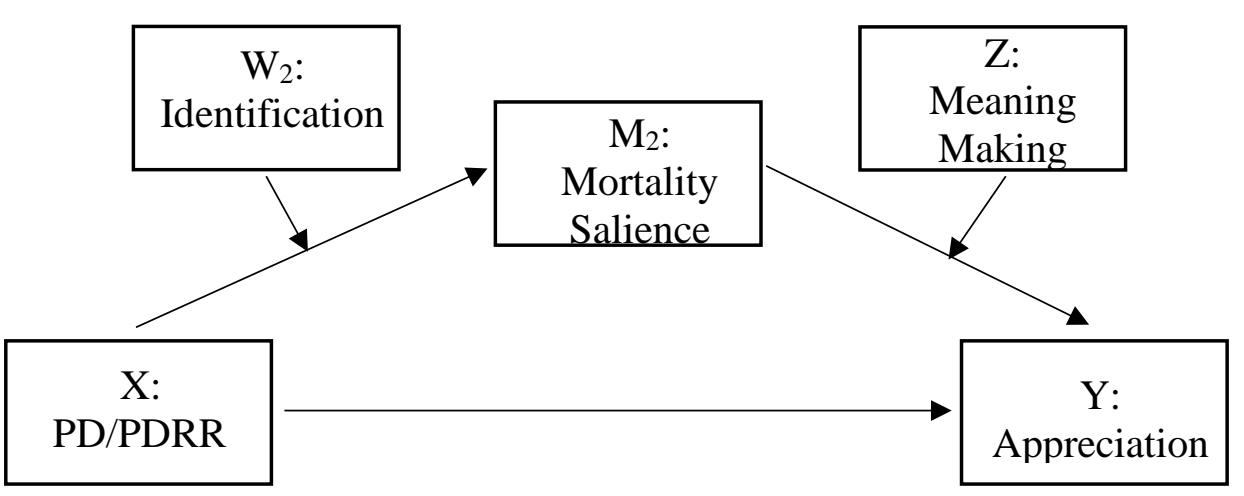




\section{CHAPTER II}

\section{Methodology}

\section{Participants}

400 video game players were recruited for this research from various discussion forums, or subreddits, on Reddit.com. Specifically, players were recruited from subreddits that focused on video game-related topics, mechanics, and games (e.g., r/xbox, r/skyrim), and because PD was an important element of this study, many players were also recruited from subreddits that specifically pertained to PD games, mechanics, and communities (e.g., r/XCOM2 and r/fireemblem). Upon completion of the study, participants had the opportunity to enroll in a gift card drawing wherein 8 different $\$ 100$ Amazon gift cards were distributed (see Appendix C). Ultimately, data from 6 players was dropped due to their not completing most measures, indicating they had not actually spent time playing with their character, or for demonstrating acquiescence response bias (i.e., selecting " 5 " on all responses). Cutting these responses ultimately yielded 394 players' reports for data analysis, with 196 players reporting on a PD and 198 players reporting on a temporary death. On average, players in this study ranged from 18 to 65 years old $(M=26.358, S D=7.953)$, and they were predominantly white $(76.4 \%)$, male $(69.8 \%)$, and lived in the United States (51.3\%).

\section{Data Collection Procedures}

After obtaining approval from West Virginia University’s institutional review board, I secured permissions from the various subreddit moderators to advertise on their subreddits. I posted a study advertisement (see Appendix A) via these subreddits requesting players to complete a 25-minute survey on their experiences with character 
death in video games. The advertisement informed potential participants that there were three criteria they must meet to be eligible to participate in the study. First, participants needed to be 18 years or older. Second, they should have played at least one role-playing game with PD mechanics in it and experienced a permanent loss of a game character within the previous year. Importantly, it was necessary that players reported on a "true" PD experience (i.e., one where their characters actually permanently died), and so players were required to have a PD experience in which they did not cheat (e.g., manipulating save file data) to prevent losing their characters. Finally, they should have also experienced a non-permanent loss of a game character within the previous year. The study advertisement also included a link to the Qualtrics-hosted online survey.

The first page of the survey contained a cover letter informing participants about the study and their rights as a research participant (see Appendix B). After consenting, players were first asked to verify that they had recently experienced a PD and temporary death, and those who indicated they had not experienced both these deaths were excluded from the study. Afterward, players were assigned to either a PD or PDRR condition, and they were asked to describe a death of one of their game characters that was respective of their study condition. Specifically, players in the PD game condition were prompted to think about their most memorable experience playing a PD game and having a character die, while those players in the PDRR condition were asked to think about a memorable temporary character death that they remembered vividly. In other words, participants in both conditions answered the exact same questions, but some were assigned to report on a memorable PD death and some were assigned to report on a memorable PDRR temporary death. 
Participants in both conditions were asked to provide the name of their character and its respective game, and they were also asked to describe who the character was, how the character died, and how they personally felt after the character died. These writing prompts were meant to help prime participants, and elicit concrete memories for players that would assist them in more accurately recalling their gameplay experiences (see Semin \& Smith, 1999), as well as many of the emotional (e.g., grief) and psychological (e.g., MS) experiences pertinent to this study. Most players reported on a character death that occurred within a few weeks of taking the survey $(43.4 \%)$ or within a few months $(30.2 \%)$. Because players were also asked to provide the name of the game in which the death occurred, this information permitted me to determine whether players had the ability to customize their character (i.e., avatar characters) or whether the game provided pre-created characters (e.g., Mario) instead, with little-to-no customization opportunities for players (i.e., agents; see Goldberg, 1998). There was no significant difference between game death type (PD vs. PDRR) and whether the games offered players the ability to customize their characters, but players ${ }^{2}$ in this study did report more on games with customizable avatar characters $(60.6 \%)$ in general than they did non-customizable agent characters $(34.2 \%), \chi^{2}(2)=21.695, p<.001$, Cramer's $V=.235$. The online survey also included questions about participants' level of identification and parasocial attachment to their deceased character, their MS (as measured by death-thought accessibility after contemplating their character's death), their grief after losing their character, their level of appreciation for the game, their predisposition to make meaning out of negative events, and their demographic information.

\section{Instrumentation}


The measures for the variables of interest are described below. For each of the following measures ${ }^{3}$ (where applicable), a confirmatory factor analysis (CFA) was run to assess the validity of each factor structure. Each CFA was tested using Maximum Likelihood Estimation (see Bandalos, 2018), and four indices were used to assess the global fits of the models $\left(\chi^{2}, \mathrm{RMSEA}, \mathrm{SRMR}, \mathrm{CFI}\right)$ in line with several recommendations from contemporary scholars for better research practices (Bandalos, 2018; Goodboy \& Kline, 2017). In assessing local fit, I examined each scale's correlation residuals and marked each "problematic" residual (i.e., correlation residuals with an absolute value larger than .10) that did not adhere to the recommendations provided by Kline (2016; see also Goodboy \& Kline, 2017). Finally, McDonald's coefficient omega statistic was also calculated using the statistical package, Jamovi, and was used in place of the Cronbach's alpha statistic to examine measurement reliabilities for this study as McDonald's omega more accurately represents a scale's reliability (McDonald, 1999).

Parasocial relationship strength. Players' parasocial attachment to their characters was measured using a subscale from Tukachinsky’s (2010) Multiple PSR Scale. This multidimensional scale was designed to measure the extent users feel they have pseudo-relationship feelings for a media figure in four different ways: (1) friendship communication and (2) support, and (3) physical and (4) emotional love. The support subscale was ultimately selected for the operationalization of parasocial attachment for this study as its items aligned most with the study's conceptualization of PSR ${ }^{4}$. A sample item for this subscale was "If [name of character] was a real person, I could trust him/her completely." Responses to this scale could range from 1 (Strongly Disagree) to 7 (Strongly Agree), with the mean value for this study being $4.616(S D=1.508$; 
McDonald's $\omega=.915)$. Previous Cronbach's alpha reliabilities for this scale have ranged from .890 to .950 (Rosaen \& Dibble, 2017; Tukachinsky, 2010). A confirmatory factor analysis (CFA) was also run to examine the factor structure of this subscale. There was mixed support for the global fit of the subscale, and problematic issues with its local fit can be seen in Table 1.

Table 1. Correlation Residuals for Parasocial Attachment

\begin{tabular}{lccccc}
\hline Items & 2 & 3 & 4 & 5 & 6 \\
\hline 1 & $\mathbf{3 2 6}$ & .025 & -.019 & -.013 & $\mathbf{- . 1 0 6}$ \\
2 & - & $\mathbf{. 1 2 8}$ & -.028 & -.063 & -.055 \\
3 & - & .021 & -.021 & .006 \\
4 & & - & .203 & -.046 \\
5 & & & - & -.060 \\
6 & & & & - \\
\hline Note. $\chi^{2}(14)=108.000, p<.001 ;$ CFI $=.946 ;$ & SRMR $=.034 ;$ RMSEA $=.131(\mathrm{CI}: .108, .154)$
\end{tabular}
Bold loadings represent problematic loadings that were above .10 in the matrix.

Identification. In similar fashion to other recent video game research (e.g., Song \& Fox, 2016), players' identification with their characters was measured using an adapted version of Cohen's (2001) 10-item Identification Scale. This scale consists of items that tap into the extent that players cognitively adopt the perspective of a character, emotionally empathize with the character, and the extent that they felt absorbed while playing as the character. For this study, piped text was used to situate player-reported character names into items, with a sample item for this scale being "While playing, I could feel the emotions [name of character] portrayed." Responses to this scale could range from 1 (Strongly Disagree) to 7 (Strongly Agree), with the mean value for this study being $5.139(S D=1.178$; McDonald's $\omega=.871)$. Previous Cronbach's alpha reliabilities for this scale have ranged from .890 to .910 (Moyer-Gusé, Chung, \& Jain, 2011; Song \& Fox, 2016). A confirmatory factor analysis (CFA) was also run to examine the factor structure of this scale. There was mixed support for the global fit of the scale, 
and potentially problematic issues with its local fit can be seen in Table 2 .

Table 2. Correlation Residuals for Identification

\begin{tabular}{lccccccccc}
\hline Items & 2 & 3 & 4 & 5 & 6 & 7 & 8 & 9 & 10 \\
\hline 1 & $\mathbf{. 3 2 6}$ & .025 & -.019 & -.013 & $\mathbf{- . 1 0 6}$ & -.039 & .024 & .038 & .068 \\
2 & - & $\mathbf{. 1 2 8}$ & -.028 & -.063 & -.055 & -.036 & .006 & -.005 & .010 \\
3 & & - & .021 & -.021 & .006 & -.067 & .025 & -.019 & .050 \\
4 & & & - & $\mathbf{. 2 0 3}$ & -.046 & .004 & -.052 & -.024 & -.059 \\
5 & & & & - & -.060 & -.029 & -.019 & .008 & -.043 \\
6 & & & & & - & .099 & .009 & -.047 & -.031 \\
7 & & & & & - & .016 & -.046 & -.045 \\
8 & & & & & & - & -.009 & .012 \\
9 & & & & & & - & .290 \\
\hline Note. $\chi^{2}(35)=313.000, p<.001 ;$ CFI $=.830 ;$ SRMR $=.070 ;$ RMSEA $=.014(\mathrm{CI} .128, .157)$
\end{tabular}

Bold loadings represent problematic loadings that were above .10 in the matrix.

Mortality salience. Players' MS was measured using an adapted version of the death theme accessibility measure used in Greenberg et al. (1994). Because one purpose of this study was to test whether PD could invoke MS in players, it was important not to directly ask participants about their levels of MS as this would prime them to be more MS. Thus, Greenberg et al.'s (1994) measure was used since it could assess the extent people were thinking about death (i.e., having death-related thoughts) without explicitly asking them to think about death. For this measure, players completed a set of 20 word fragments by filling in missing letters from each word. Seven of the 20 word fragments could potentially be completed as either a neutral word or one that was death-related (e.g., sk_ll could either be "skill" or "skull"), and the number of death-related words players provided were summed together to create a composite score ranging from 0 (No $M S)$ to 7 (High MS), with the mean value for this study being $1.878(S D=1.084)$. Mean scores for this scale in the past have ranged from 0.062 to 3.830 (Arndt et al., 1997; Greenberg et al., 1994).

Grief. Players' grief in response to losing their characters was assessed via an adapted version of Faschingbauer, Zisook, and DeVaul's (1987) Texas Revised Inventory 
of Grief. This bidimensional scale measures two separate components of grief: (1) past behaviors people may have undergone in response to their loss and (2) present feelings they may still have regarding that loss. However, for the purposes of this study, only the present feelings subscale was used for analyses as I was primarily concerned with the feelings of grief players had when currently thinking of the deaths of their characters, after completing the written prime. To adapt this subscale for this study, all language representing "this person" was replaced with piped text using player-reported character names. A sample item for the present feelings subscale was "I still get upset when I think about [name of character]." Responses to these subscales could range from 1 (Strongly Disagree) to 7 (Strongly Agree), with the mean value for this study being $1.890(S D=$ 1.019; McDonald's $\omega=.916$ ). Previous Cronbach's alpha reliabilities for this scale have often been found to be .900 (Caserta, Lund, Utz, \& de Vries, 2009; Utz, Caserta, \& Lund, 2011). A confirmatory factor analysis (CFA) was also run to examine the factor structure of this scale. There was mixed support for the global fit of the scale, and potentially problematic issues with its local fit can be seen in Table 3.

Appreciation. The extent players appreciated their gameplay experience was measured using an adapted version of Oliver and Bartsch's (2010) Enjoyment and Appreciation Scale. This multi-dimensional scale assesses four types of user-responses to media, namely whether users believed the media was (1) fun, (2) suspenseful, (3) moving/thought-provoking, (4) or left a lasting impression. However, for the purposes of this study, only the three-item appreciation dimension was used. A sample item for this subscale would be "I found [name of game] to be very meaningful." Responses to this scale could range from 1 (Strongly Disagree) to 7 (Strongly Agree), with the average 
response value for this study being $5.355(S D=1.485$, McDonald's $\omega=.885)$. Oliver and Bartsch (2010) originally observed previous Cronbach's alpha reliabilities ranging from .750 to .900 for this subscale.

Meaning making. The extent that participants were predisposed to engage in MM coping was measured using the meaning making subscale of Gan, Guo, and Tong's (2013) Meaning-Focused Coping Questionnaire. This questionnaire asks people to consider how they tend to react when they encounter stressful life events. A sample item for this study was "I wonder whether there is some special meaning in the occurrence of stressful events." Responses to this scale could range from 1 (Strongly Disagree) to 7 (Strongly Agree), with the average response value for this study being $4.990(S D=1.288$ McDonald's $\omega=$.818). Gan et al. (2013) originally found a Cronbach's alpha reliability of .789 for this subscale. A confirmatory factor analysis (CFA) was also run to examine the factor structure of this scale. Besides the $\chi^{2}$ test statistic, which commonly punishes large sample sizes of data (see Bandalos, 2018), the global fit statistics for this study indicated the scale fit the data for this study, and no potentially problematic issues with local fit were found (see Table 4). 
Table 3. Correlation Residuals for Grief

\begin{tabular}{lcccccccccccc}
\hline Items & 2 & 3 & 4 & 5 & 6 & 7 & 8 & 9 & 10 & 11 & 12 & 13 \\
\hline 1 & -.033 & -.072 & -.042 & -.029 & .007 & $\mathbf{. 1 0 3}$ & .030 & .010 & $\mathbf{- . 1 1 6}$ & .001 & -.095 & $\mathbf{. 1 0 8}$ \\
2 & - & .064 & $\mathbf{. 1 9 6}$ & $\mathbf{. 1 5 1}$ & -.092 & -.071 & -.051 & -.062 & $\mathbf{. 1 6 4}$ & .015 & .002 & $\mathbf{- . 1 0 7}$ \\
3 & & - & .018 & .047 & -.039 & -.063 & -.063 & -.098 & $\mathbf{. 1 3 2}$ & -.016 & $\mathbf{. 3 0 9}$ & -.074 \\
4 & & & - & $\mathbf{. 1 0 2}$ & -.006 & -.077 & .000 & -.050 & .090 & $\mathbf{. 1 1 0}$ & -.040 & $\mathbf{- . 1 0 9}$ \\
5 & & & & - & -.052 & -.005 & -.013 & -.073 & .021 & .001 & .021 & -.058 \\
6 & & & & & - & -.034 & -.010 & $\mathbf{. 1 4 1}$ & -.015 & -.003 & -.016 & .052 \\
7 & & & & & & - & .051 & -.031 & -.096 & -.043 & -.057 & $\mathbf{. 1 3 4}$ \\
8 & & & & & & & - & $\mathbf{. 1 6 3}$ & -.057 & .010 & $\mathbf{- . 1 0 2}$ & -.013 \\
9 & & & & & & & & - & -.035 & -.001 & -.037 & .043 \\
10 & & & & & & & & & - & .028 & $\mathbf{. 1 2 8}$ & -.092 \\
11 & & & & & & & & & & - & -.020 & -.026 \\
12 & & & & & & & & & & & - & -.010 \\
\hline
\end{tabular}

Note. $\chi^{2}(65)=624.000, p<.001 ;$ CFI $=.798 ;$ SRMR $=.070 ;$ RMSEA $=.148$ (CI: $\left..137, .158\right)$

Bold loadings represent problematic loadings that were above .10 in the matrix.

Table 4. Correlation Residuals for Meaning Making

\begin{tabular}{lccc}
\hline Items & 2 & 3 & 4 \\
\hline 1 & .002 & .006 & -.036 \\
2 & - & -.009 & .022 \\
3 & & - & .021 \\
\hline Note. $\chi^{2}(2)=3.830, p=.015 ;$ CFI $=.997 ;$ SRMR $=.013 ;$ RMSEA $=.048$ (CI: .000, .121$)$
\end{tabular}




\section{CHAPTER III}

\section{Results}

\section{Exploratory Analyses}

Prior to the hypothesis tests, an in-depth examination of the relationships between this study's variables was performed, and below, a brief outline of noteworthy relationships ${ }^{5}$ is provided. Descriptive statistics and a correlation matrix between the variables for this study can be found in Table 6

First, players who reported on PDs expressed greater parasocial attachment to their characters, $r(392)=.220, p<.001$, and reported experiencing greater grief, $r(392)=$ $.226, p<.001$. PD players also exhibited increased MS, $r(392)=.065, p=.198$, and appreciation, $r(392)=.116, p=.021$, but decreased identification with their character, $r(392)=-.076, p=.135$. Players who were more parasocially attached to their characters reported identifying with those characters more $r(392)=.572, p<.001$, as well as experiencing increased MS, $r(392)=.135, p=.007$, grief $r(392)=.349, p<.001$, and appreciation for their gameplay experience, $r(392)=.423, p<.001$. There was also a positive correlation between parasocial attachment and trait meaning making, $r(392)=$ $.257, p<.001$

Players who identified more with their characters experienced increased MS in this study, $r(392)=.117, p=.020$. Player identification was also positively related to grief, $r(392)=227, p<.001$, appreciation, $r(392)=.473, p<.001$, and trait MM, $r(392)$ $=.283, p<.001$. MS was positively correlated to grief, $r(392)=.204, p<.001$. Additionally, there was a positive association between grief and appreciation, $r(392)=$ $.313, p<.001$, and between grief and trait MM, $r(392)=.298, p<.001$. 
Table 5. Summary of Descriptive Statistics and Correlations of Study Variables

\begin{tabular}{|c|c|c|c|c|c|c|c|c|c|c|c|c|}
\hline Variables & 1. & 2. & 3. & 4. & 5. & 6. & 7. & 8. & 9. & 10. & 11. & 12 \\
\hline 1. Death Type $(0=\mathrm{PD})$ & - & $.220 * * *$ & -.076 & .065 & $.226^{* * *}$ & .080 & $.116^{*}$ & .006 & $-.104 *$ & $.299 * * *$ & $-.149 * *$ & .022 \\
\hline 2. Parasocial Attachment & & - & $.572 * * *$ & $.135 * *$ & $.349 * * *$ & $.257 * * *$ & $.423 * * *$ & -.064 & .072 & .088 & $-.143 * *$ & .047 \\
\hline 3. Identification & & & - & $.117 *$ & $.227 * * *$ & $.283 * * *$ & $.473 * * *$ & -.079 & $.117 *$ & -.022 & -.052 & .086 \\
\hline 4. Mortality Salience & & & & - & $.204 * * *$ & .032 & .097 & .027 & -.037 & -.004 & $-.160 * *$ & -.050 \\
\hline 5. Grief & & & & & - & .062 & $.313 * * *$ & -.083 & $.146 * *$ & $.129 *$ & -.069 & -.007 \\
\hline 6. Meaning Making & & & & & & - & $.298 * * *$ & -.042 & .013 & .008 & -.021 & .085 \\
\hline 7. Appreciation & & & & & & & - & -.001 & .010 & .049 & -.081 & .030 \\
\hline 8. Player Skill & & & & & & & & - & -.065 & $-.101 *$ & -.018 & .014 \\
\hline 9. Time with Character & & & & & & & & & - & -.012 & $.275^{* * * *}$ & -.048 \\
\hline 10. Death Recency & & & & & & & & & & - & -.011 & .003 \\
\hline 11. Age & & & & & & & & & & & - & .040 \\
\hline 12. Sex & & & & & & & & & & & & - \\
\hline$M$ & - & 4.320 & 5.139 & 1.878 & 1.890 & 4.990 & 5.355 & 4.575 & 121.215 & 1.906 & 26.358 & - \\
\hline$S D$ & - & 1.669 & 1.178 & 1.084 & 1.019 & 1.288 & 1.485 & 1.212 & 456.353 & .959 & 7.953 & - \\
\hline
\end{tabular}

Note. $* p<.05, * * p<.01, * * * p<.001$; Values pertaining to biological sex are biserial correlations (Male $=0$ ). 


\section{Hypothesis Tests}

All of the hypotheses were tested using Hayes' (2018a) PROCESS macro (version 3.4) for SPSS. In each of the models that were tested, players' age, biological sex, time spent with their game characters, self-reported video game skills, and the recency of characters' deaths were entered as control variables.

$\mathrm{H} 1$ predicted that the indirect effect of $\mathrm{PD} / \mathrm{PDRR}$ on appreciation through grief would be moderated by both PSR (first-stage moderation) and meaning making coping style (second-stage moderation). Similarly, $\mathrm{H} 2$ predicted that the indirect effect of PD/PDRR on appreciation through MS would be moderated by both identification (firststage moderation) and meaning making coping (second-stage moderation). To examine both of these predictions, separate conditional process models (Model 21; Hayes, 2018a) were run using 5,000 bootstrapped samples and $95^{\text {th }}$ percentile confidence intervals. Following procedures outlined by Hayes and Rockwood (2020; see also Hayes, 2018b), the index of moderated moderated mediation was first examined for each model to determine whether the relationship between the first-stage moderators (parasocial attachment, identification) and the strength of their respective mediators (grief, MS) varied as a function of their second-stage moderator (meaning making). If either index' confidence interval excluded zero, indicating the presence of moderated moderated mediation, that model's index of conditional moderated mediation was then examined to explore the underlying nature of the conditional moderated indirect effect. This second index estimates the moderation of each first-stage moderator at different values of meaning making (at values calculated at the data's $16^{\text {th }}, 50^{\text {th }}$, and $84^{\text {th }}$ percentiles). 
Table 6. OLS Regression Coefficients (with standard errors) from the Moderated Moderated Mediation of the DeathAppreciation Relationship through Grief

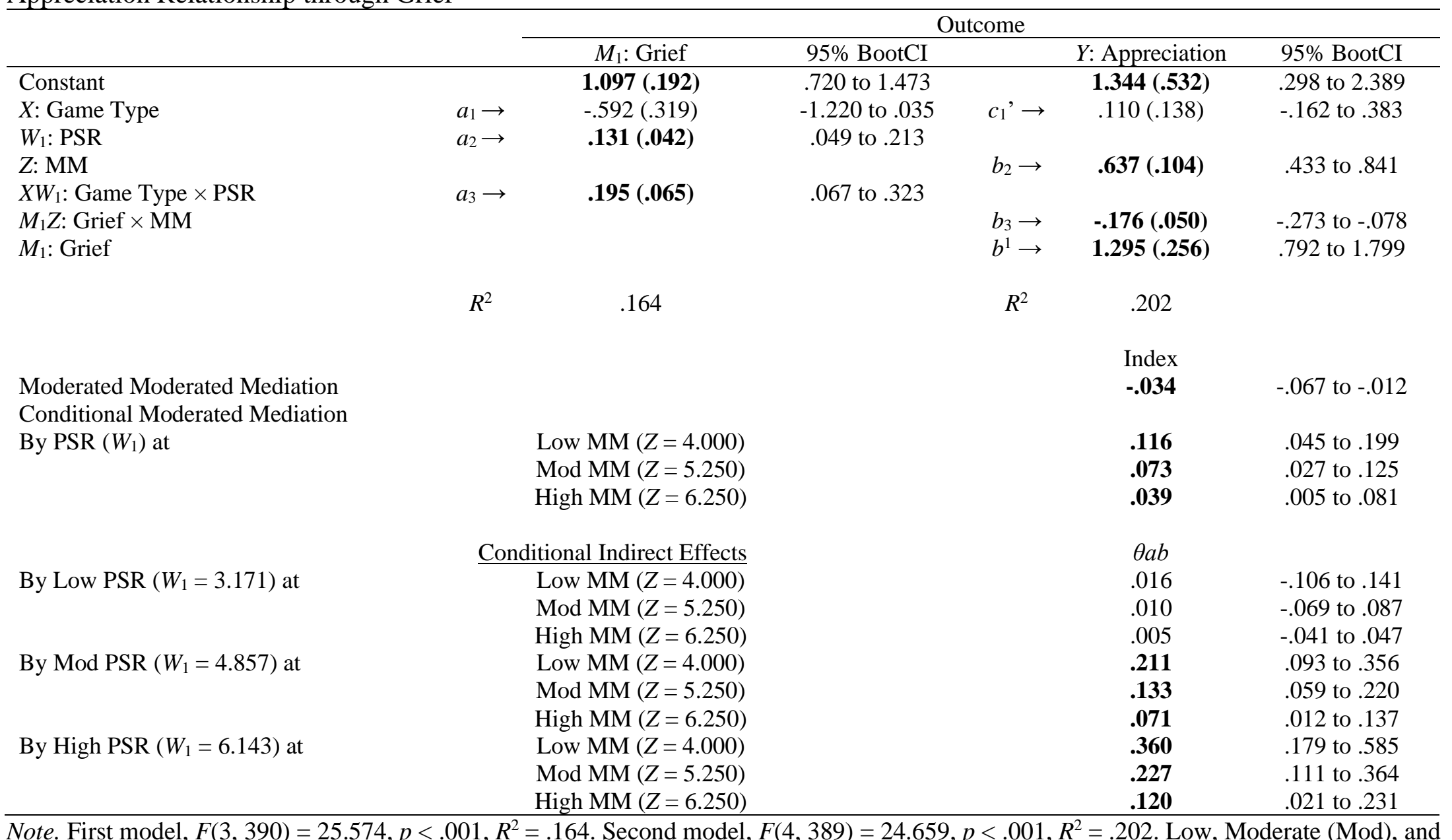

High values were calculated at the $16^{\text {th }}, 50^{\text {th }}, \& 84^{\text {th }}$ percentiles. Bold-faced coefficients indicate that their confidence interval did not contain zero. Percentile bootstrap CI was based on 5,000 bootstrap samples. 
Regarding H1, which predicted that the indirect effect of PD/PDRR (X) on appreciation $(\mathrm{Y})$ through grief $\left(\mathrm{M}_{1}\right)$ would be moderated by both PSR $\left(\mathrm{W}_{1}\right)$ and meaning making coping style $(\mathrm{Z})$, there was evidence of moderated moderated mediation (index of moderated moderated mediation $=-.034$, BootCI: $-.067,-.012$ ). An examination of the indices of conditional moderated mediation revealed that at low $(\mathrm{MM}=4.000$; index of conditional moderated mediation $=.116)$, moderate $(\mathrm{MM}=5.250$; index of conditional moderated mediation $=.073)$, and high $(\mathrm{MM}=6.250$; index of conditional moderated mediation $=.039)$ levels of trait MM, players' appreciation for their gameplay experiences increased when mediated by the grief for the deaths of their characters that was moderated by their parasocial attachment to those characters. In other words, as players became more attached to their characters, the grief they felt for those characters' deaths increased their appreciation for their gameplay experience. However, contrary to expectations, the strength of this conditional moderated indirect effect actually decreased as players' trait MM increased, meaning the impact of players' grief on their appreciation for the game experience, when moderated by parasocial attachment, was lessened (though still positive) for players predisposed to MM. The full model's details can be found in Table 7. H1 was not supported.

Regarding $\mathrm{H} 2$, which predicted that the indirect effect of PD/PDRR (X) on appreciation $(\mathrm{Y})$ through MS $\left(\mathrm{M}_{2}\right)$ would be moderated by both identification $\left(\mathrm{W}_{2}\right)$ and meaning making coping $(\mathrm{Z})$, there was no evidence of moderated moderated mediation (index of moderated moderated mediation $=-.005$, Boot CI: $-.033, .024)$. In other words, MS did not mediate the relationship between PD experiences and appreciation, nor were any such effects moderated by players' identification with their characters. There was, 
however, an interaction between players' MS and trait MM on their appreciation of their gameplay experiences $\left(b=-.147\right.$, Boot $\left.\mathrm{SE}=.055, \Delta R^{2}=.016, \mathrm{CI}:-.255,-.040\right)$. Specifically, at low levels of trait MM $(\mathrm{MM}=4.000)$, the relationship between players' $\mathrm{MS}$ and their appreciation for their gameplay experiences increased $\left(\theta_{(\mathrm{X} \rightarrow \mathrm{Y})}=.254\right.$, BootSE $=.084, \mathrm{CI}: .089, .419)$. However, this moderation effect was not significant for players at moderate $\left(\mathrm{MM}=5.250 ; \theta_{(\mathrm{X} \rightarrow \mathrm{Y})}=.070,{ }_{\text {Boot }} \mathrm{SE}=.067, \mathrm{CI}:-.062, .202\right)$ nor high $\left(\mathrm{MM}=6.250 ; \theta_{(\mathrm{X} \rightarrow \mathrm{Y})}=-.078,{ }_{\text {Boot }} \mathrm{SE}=.096, \mathrm{CI}:-.266, .111\right)$ levels of trait MM. In other words, players appreciated their gameplay experiences more as their MS increased, but this was only the case for individuals who scored the lowest in terms of trait MM (accounting for $24.6 \%$ of the sample). The full model's details can be found in Table 8 . H2 was not supported. 
Table 7. OLS Regression Coefficients (with standard errors) from the Moderated Moderated Mediation of the DeathAppreciation Relationship through Mortality Salience

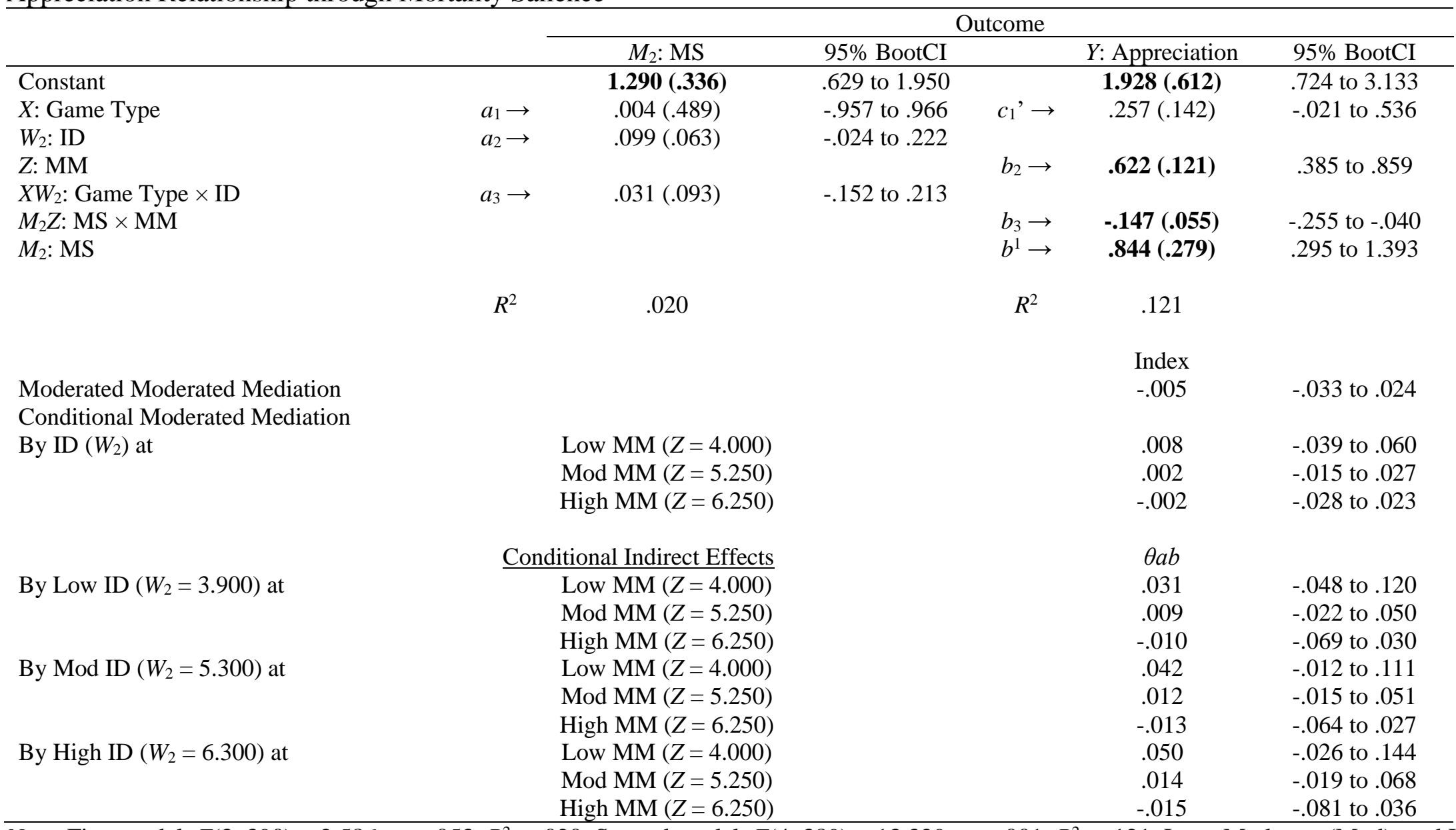

Note. First model, $F(3,390)=2.586, p=.053, R^{2}=.020$. Second model, $F(4,389)=13.329, p<.001, R^{2}=.121$. Low, Moderate (Mod), and High values were calculated at the $16^{\text {th }}, 50^{\text {th }}, \& 84^{\text {th }}$ percentiles. Bold-faced coefficients indicate that their confidence interval did not contain zero.

Percentile bootstrap CI was based on 5,000 bootstrap samples. 


\section{CHAPTER IV}

\section{Discussion}

People play video games for a variety of reasons (Sherry et al., 2006; Yee, 2006), but one of the common features of most player's gameplay experience is that they play using a video game character. Some players care for these characters as little more than the pawns on their screen that perform their bidding (Banks, 2015), but for others, a much more intimate type of attachment may form (Song \& Fox, 2016), especially when players have the ability to lose these characters forever as a consequence of PD mechanics. This study was premised on the argument that players' motivations for playing these PD games stem, in part, from their ability to gain an increased sense of appreciation for their gameplay experiences through a meaningful permanent character death experience. I have argued that such appreciation would arise due to PDs invoking the difficult and challenging, but potentially meaningful, experiences of grief for their characters and the heightened salience of their own, personal mortalities. I have also argued that the extent players experienced grief and MS would be conditional, respectively, upon the level of two distinct types of attachment they to their characters: parasocial attachment and identification. Lastly, I predicted that the extent players experienced appreciation through grief and MS would also be conditional upon players' MM tendencies. Altogether, there were several key, theoretical findings that arose from this dissertation that can aid researchers to better understand the phenomenon of $\mathrm{PD}$ in gaming.

This study proposed that players may seek out PD experiences because they are more meaningful than temporary deaths, thereby increasing the appreciation players can derive by playing them. Although reporting on a PD experience was positively correlated 
with appreciation, this study's analyses did not find any direct effect of game type on appreciation after accounting for the other study variables. PD did, however, have a conditional indirect effect on appreciation which helps sheds light on exactly how a PD experience can translate into a meaningful experience.

As predicted, PD did increase players' grief for their dead characters, and in turn, that grief increased players' appreciation for their gameplay experiences, an effect that was conditional on both PSR and MM. This indirect effect was strengthened by players' feelings of attachment to their characters, but it decreased for players the more prone they were to make meaning from their experiences. These findings do make some intuitive sense. Similar to how people grieve for real-life others (Kübler-Ross, 1969), players who experience PD also grieve for their characters when they die, albeit to a lesser extent. Nonetheless, this grief players feel seems to help them gain more meaning from their gameplay experiences as they ponder life's purpose and the human condition, especially when players are attached to their characters. While grief for a character may not be a pleasant experience in any sort of hedonic sense, this finding lends some support to it being a moving, eudaimonic experience under the right conditions.

One condition is that players feel parasocially attached to their character, to some extent. Consistent with previous research on attachments to other types of media figures (Cohen, 2003; Cohen \& Hoffner, 2016; Eyal \& Cohen, 2006), the stronger parasocial bonds players have with their characters, the more intense grief they seem to feel upon losing their characters permanently, and the more they appreciate the experience as a result. It comes as no surprise, then, that many players who participated in this study had close, personal connections to their game characters. The time and emotional resources 
that many players invest into their characters can facilitate strong bonds (see Rusbult, 1980; Rusbult et al., 2012). It also makes intuitive sense that players would more intensely grieve for characters with whom they felt more closely attached, much like how people remain closer to those they were originally close to before leaving them (Tan, Agnew, VanderDrift, \& Harvey, 2015). So too, it makes sense that greater PSR with game characters should determine the extent that players' grief will lead to appreciation. When players grieve for characters they feel more close to, their ensuing reflections in response to that grief should be more impactful, more powerful, more moving. In summary, the results of this study show that compared to temporary character deaths, permanent character deaths trigger deeper emotional responses that can lead to more meaningful experiences as a result — at least for players who feel more parasocially bonded to their characters.

Besides PSR, the conditional indirect effect of PD on appreciation through grief was also conditional on meaning making. Notably, MM also interacted with MS to predict appreciation (though more on the MS model will be discussed below). This study reasoned that players with increased predispositions for coping by seeking meaning in their experiences would be better equipped to push past the negativity of experiences, such as grief and MS, and to find purpose in their negative experiences to derive appreciation from them. In other words, players who were more inclined look for meaning in adverse experiences were expected to report greater appreciation for the PD experience. Such a finding would have been consistent with the anxiety buffer hypothesis (see Pyszczynski et al., 2015; Rieger, 2017), as well as Juhl and Routledge's (2016) work that both rely on the same logic. Yet, the opposite finding emerged: players experienced 
less appreciation for PD experiences when they scored higher in trait MM. One explanation for this unexpected finding could be that both PD-induced grief and MS can only be appreciated by those who do not normally seek out meaning in their lives. Theoretically, it could be players with higher levels of trait MM might not have experienced greater appreciation from their grief and MS because they have been somewhat inoculated against it. If people are predisposed to finding meaning in all stressful events they undergo, including extremely stressful events (e.g., the death of a family member, losing a job), losing a character in a PD game may not seem very remarkable, by comparison. Perhaps the intensity of grief experienced in response to a PD did not reach a threshold that would trigger the natural coping response of players with MM tendencies. On the other hand, for someone low in trait MM who ordinarily is less accustomed to looking for meaning in stressful events (and likely has a different coping style), grief felt in response to a video game may be stressful, yet innocuous enough to let them process it and extract meaning from it. Of course, at this point, this is all speculation to explain a contradictory finding, and so further investigation would be needed to explore these claims.

Like grief, increased MS was also theorized to be one of the ways that PD experiences would lead to appreciation, at least conditionally. This study predicted that players reporting on a "true" death (i.e., a PD) of their characters would have increased MS compared to those reporting on a temporary death. As Pyszczynski et al. (2015) mentioned, to assuage their fears of death, people often cling to various forms of temporal and symbolic immortality to give themselves hope. Video game characters, especially PDRR characters, are very much symbolic representations of immortality as 
these characters can die and resurrect with little consequence, and so characters who can actually die seem like they would represent an antithesis to the standard type of character used in PDRR games. Following this logic, compared to a PDRR event, a permeant death was expected to boost players' MS, as permanently losing a character (i.e., having them "die") would be more likely to cause players to think of death than simply having a character resurrect mere moments after dying. Nonetheless, the type of death experience had no effect on MS in this study. This suggests that video game players are not relating their characters' deaths to their own. As Hofer (2013) argued, though media characters' deaths, at least heuristically, seem like they would be particularly adept in increasing media users' MS upon consumption, it is important to not neglect that media consumers can easily buffer themselves by mentally distancing themselves from the death experiences of their characters (e.g., "the character is dying, not me"). So perhaps, even if players do experience spikes of MS upon character deaths, they are naturally inclined to suppress that MS before any meaningful reflection can occur.

Also, contrary to expectations, players' identification with their characters did not moderate the indirect effect of death type on appreciation, nor the effect of death type on MS. Previous research has demonstrated that people are more likely to have increased MS after pondering their own deaths rather than the deaths of others (Greenberg et al., 1994), and if players identified with their characters (i.e., if they literally adopted the cognitions and emotions of their characters and felt as if they were those characters), it followed that they may have felt as if the death of their character was their own, if even only momentarily. However, although the mean value of identification in this study was high $(M=5.139$ on a 7 -point scale), indicating players found it easy to identify with their 
characters overall, identification was only related to MS to a small degree $(r=.117)$. This suggests that despite being able to identify as their game characters, players nonetheless differentiated themselves from those characters at the point of the characters' deaths. In hindsight, this makes sense for several reasons. First and foremost, the conceptualization of identification indicates that the temporal shift in identity that people may experience is only supposed to last for relatively short periods of time (Cohen, 2001; Klimmt et al., 2009), and so it is not surprising that players' temporal identity shifts would dissipate pretty quickly, especially after dying. Furthermore, even if players are more inclined to see the character as themselves, to reiterate Hofer's (2013) argument, it make senses that they would want to proximally distance themselves from the deaths of the characters in order to allay their own fears of mortality.

\section{Theoretical and Practical Contributions}

This research makes a number of notable contributions to the broader bodies of research on character attachment, eudaimonic media gratifications, and emotional experimentation using video games. Compared to typical video game character deaths which lack permanence, PDs elicit greater grief, particularly among players who are more closely bonded to their game characters. Regarding media figure attachment, this research extends a small but growing body of research demonstrating that players develop PSRs with game characters (Banks, 2015; Lewis et al., 2008; Song \& Fox, 2016). As with attachments to other media figures, the death of video game characters can take an emotional toll, especially if people are parasocially attached (Cohen, 2003; Cohen \& Hoffner, 2016; Daniel \& Westerman, 2017; DeGroot \& Leith, 2015; Eyal \& Cohen, 2006; Harrer, 2013; Sanderson \& Cheong, 2010). It is worth noting too, that 
players who reported on a PD experience reported stronger PSRs with their character $(r=$ .220). This suggests that there may be something about the PD game mechanic that enhances player-character closeness. Perhaps, for instance, it is because the possibility of characters succumbing to a "true death" causes players to view these characters as being more "alive" (Lynch \& Matthews, 2017). As Rousse (2011) originally posited, the everlooming threat of PD may stress to players the "valuable, unique, and irreplaceable" nature of these characters (for more information, see Rousse, 2011), which thereby might increase the amount of care and attention players direct toward them. As people commit to relationships that they believe will satisfy themselves and that they are already invested in (Rusbult, 1980; Rusbult et al., 2012), so too might players become more committed and attached to their characters as they perceive them to be more worthy of investment.

Concerning the uses and gratifications of video games, this study sheds further light on why, despite the grief players risk encountering, they may seek out PD game experiences. As previous uses and gratifications research has demonstrated, people make choices about their media usage based on past mediated experiences (Chen, Lin, Yen, \& Linn, 2011). By extension, it stands to reason that players of PD games may seek them out to replicate meaningful experiences they have had with these games. Consistent with research on other types of media (e.g., film and television; Bartsch et al., 2014;

Goldenberg et al., 1999; Grodal, 2007; Klimmt, 2011; Knobloch-Westerwick et al., 2012; Oliver, 1993, 2008; Oliver \& Bartsch, 2010; Oliver \& Hartmann, 2010; Perloff, 2016; Wirth et al., 2012) this study provides further evidence that even aversive affective states - such as grief felt in response to permanent character deaths - can lead to an 
increased sense of appreciation for video game experiences, especially PD experiences. Thus, in accordance with Carter and Allison's (2017) findings, the results from this study indicate that players are likely driven to seek out PD games not just for the sake of enjoyment, but also because of the meaningful experiences that they provide to players as well.

This work also adds a relatively new area of research on the eudaimonic processes in video game contexts (e.g., Bowman et al., 2016; Oliver et al., 2015). Specifically, this study demonstrates that, under the right conditions, the PD video game mechanic is wellsuited to foster meaningful gameplay experiences through the experience of grief. Additionally, although MS did not mediate the effect of PD on appreciation, it is also worth noting that players experiencing greater MS did report appreciating their game experiences more - an effect that was conditional on low levels of trait MM. This provides some hint that MS may be one of the factors that leads to more meaningful media experiences, at least for some media consumers.

This research also enhances our understanding of how video games can function as important experimental playgrounds for players, providing a safe space to explore intense emotions and other experiences (see Jansz, 2005; Ryan et al., 2006). In the case of PD games, players are given an opportunity to experiment with relatively (compared to PDRR games) high-stakes risks, and to wrestle with emotions like grief. That players did not report experiencing very much grief after the loss of their characters could indicate that games do not elicit particularly intense emotional responses while playing. This is not particularly surprising considering that these games are, after all, just games, and even "true" permanent deaths, are not real deaths. But the artificiality of these 
experiences is why PD games may be particularly well-suited for helping players cope with different emotional experiences. Jansz (2005) has argued that part of the appeal of video games is they afford players a great deal of control over the emotions they experience, allowing them to experience and experiment with different emotional management strategies in their own "private laboratories" (p. 231). In this way, confronting PD in a video game could allow players to grapple with real-world—albeit less intense-emotions and struggles productively in a space that is physically and psychologically safe. As previously discussed, the finding that only people with lower levels of trait MM were able to process their PD-elicited grief in a way that resulted in appreciation suggests that these players might have benefited the most from being able to experience these negative emotions tied to the game world, while still maintaining a comfortable difference from grief in their real world. Examining PD as an emotional coping tool is a topic ripe for future research. Does allowing players to confront topics such as grief and death within video games - in this case, PD games - better prepare players to face these issues in the physical world? In line with the anxiety buffer hypothesis (see Pyszczynski et al., 2015; Rieger, 2017), video games could serve as an efficient tool for helping people to come to terms with their own impending deaths in a manner that would not necessarily cripple there physical and psychological productivity.

One practical implication of these findings would be that because players ultimately appreciated their gameplay experiences more when they reported on a PD, having expendable characters in a game seems to add an important and meaningful element to it that may inherently increase the game's desirability and value to players. In an industry wherein there is no shortage of new games to play and buy, purchase- 
decisions are often influenced by customers seeking out word-of-mouth reviews from friends and online reviews (Bounie, Bourreau, Gensollen, \& Waelbroeck, 2008; Hernandez \& Vicdan, 2014; see also Watts, West, \& Bowman, 2018), and game developers are therefore constantly seeking out new features and mechanics that may set their game apart from others, it may not be enough to simply provide just an enjoyable experience anymore. Rather, game developers may want to begin implementing PD mechanics within their games. Through making their characters more "valuable, unique, and irreplaceable" (Rousse, 2011) and "alive" (Lynch \& Matthews, 2017) by subjecting them to PD mechanics, not only would developers' games' replayability values increase (see Parker, 2017), but players' appreciation of those games would increase too, likely increasing the chances players would share their experiences with other potential customers as they attempt to help those players also have positive gaming experiences (see Cheung \& Lee, 2012). To further support this point, even a quick cursory glance at players' "most memorable game experiences" lists throughout the industry (see Gordon, 2016; Russo, 2016; Senior, 2019) reveals one interesting commonality: the permanent deaths of important and prominent story characters. Thus, for game developers hoping to have their games stand out in an over-saturated marketplace, these findings suggest that working to incorporate PD in future games should serve to bolster player support for those games as players increasingly appreciate their overall gameplay experiences.

\section{Limitations and Future Directions for Research}

This research has several limitations and opportunities for future research which should be considered. First, this study was unable to capture immediate player responses to character deaths, and instead, relied on players recalling these death events several 
weeks to months after their actual death experiences occurred. As such, these findings represent players' recall of their death experiences rather than their actual responses to those death experiences, which means this data is likely subject to participant response bias that may undermine its validity. For instance, Trope and Liberman (2010) explained that people's memories of experiences can become more mundane and less intense as those events become more temporally distance, and so in the case of recall-generated research, it would be likely that participants' responses would only serve to represent a fraction of the original experiences. Through this lens of looking at this study's data, this would mean that players' death-related experiences might actually be more intense than was found (e.g., players may have experienced increased grief and MS in response to losing their characters than they reported). However, Trope and Liberman also discussed how certain emotional experiences may not be subject to the same levels of emotional mitigation or suppression, as people likely remember more intense emotions they have experienced (e.g., grief felt from losing a loved one) easier than less intense emotions (e.g., happiness felt from receiving a gift from someone). Nonetheless, given that our understanding of construal levels and their effects is still developing at this time, our understanding of this data's validity is limited by its recall nature ${ }^{6}$.

Another limitation to this study is that there is evidence that some participants may have been confused by the survey questions. In their public responses to the survey on Reddit.com, some PDRR players reported experiencing intense negative affect toward having to respond to the PSR/grief-related items. In other words, these PDRR players expressed confusion or discomfort responding to certain items that would have applied more to players who experienced PDs, such as responding to the grief-related item 
"Sometimes, I very much miss [name of character]" even though their character was simply resurrected moments later (e.g., dying in a Mario game). Often expressing that I was asking questions about the "wrong game" to the "wrong type of players," these PDRR players expressed that the PSR/grief items were extremely foreign to their gameplay experiences as they "did not know they should care so much about Mario dying" repeatedly. Importantly, the fact that these players seemed uncertain about how to respond to these items does lend some support to this study's contention that PD games offer a categorically different experience than PDRR games, as the core rationale behind this dissertation was to demonstrate that players will respond differently to permanently losing their PD characters than they will to repeatedly losing characters like Mario (for a further discussion of this issue, see West et al., 2019). However, to these PDRR players' point, it is important to acknowledge that it is at least possible that some of the differences observed in this research between reports on PDRR and PD experiences could be an artifact of participants' difficulty reporting on PDRR "deaths."

Another limitation of this study was that it used a convenience sample of players found within the gaming subreddits of Reddit.com. Given that the study was only available for a few weeks within a few distinct subreddits, these findings represent a sample of players who were active community members at a given time on these forums. Players were also allowed to self-select into the study, meaning that participants may have had particular interest in influencing the data for this study by expressing themselves. Though these factors do not necessarily limit this study's ability to explain the various relationships and conditional processes between PD experiences and players' appreciation for gameplay, they do limit its generalizability to the overall player base. For 
instance, many players with varying opinions were excluded from this study on the basis that they may not have wanted to participate, or because they simply may not participate on Reddit.com.

Moving on, an additional limitation of this study that is common to all survey designs was that because the data for this study was cross-sectional, they were unable to establish concrete evidence of the time-order of variables presented in this study's conditional process models. It could be that because, in some cases, players had ample time to think about their characters' deaths before reporting on them (up to a year), players may have actually reported feeling increased grief in response to their characters' deaths because of the appreciation they felt upon losing those characters. Kaplan, Levine, Lench, and Safer (2015) recently observed that people's recall of emotional and mood intensities become skewed — both positively and negatively — as time passes from previous events, and therefore, it is entirely feasible that players may have simply overestimated their grief in response to recalling their characters' deaths, especially if they perceived those deaths as being meaningful.

Another limitation worth noting was that - with the exception of Gan et al.'s (2013) 4-item MM subscale - the measures used for obtaining data in this study had several global and local issues with their factor structures. One explanation for this limitation could be that because many of the measures used for this study were not specifically created for use in the context of video games and game characters, a level of systematic error variance was introduced into these findings. However, another explanation could be that these measurements issues are not specific to this study, but rather, are evidence of a larger issue with variable measurement within the field of 
communication. As recent communication scholars have noted (see Goodboy \& Kline, 2017), many communication scales are created for short-term research purposes and then simply re-used by later researchers, but their factor structures are rarely tested to ensure their validity and replicability ${ }^{7}$. That this study did perform CFAs for every scale — to abide by better research practice recommendations (see Bandalos, 2018; Goodboy \& Kline, 2017) — these findings may just serve as a confirmation that several of these scales may need to be revisited by future researchers.

Another limitation of this research is that there is no way of determining if the Greenberg et al.'s (1994) death theme accessibility measure was truly tapping into players' personal mortality salience. Greenberg et al.'s measure is intended to examine the extent people are thinking about death, but this does not necessarily mean that the measure assesses players' thoughts of their own deaths (i.e., their MS). For instance, players see death in games in many forms through the deaths of their own characters, friendly non-playable characters, and enemy characters. Thus, when players completed Greenberg et al.'s measure, it could have been that they were thinking about any of these various deaths throughout their gameplay experiences, but it is impossible to indicate that they were thinking of their own deaths, specifically. To be clear, it is not this study did not capture any players' contemplations of their own mortalities within its data; rather, I was unable to parcel out players' MS thoughts from other general death-related thoughts. In looking forward to future directions for PD-related research, one obvious need would be to further tease-apart any possible differences between PDs and temporary death experiences. For instance, several of the rationales in this manuscript were based on the assumption that PD experiences are perceived as more realistic by players than 
temporary death experiences; however, there has been no empirical work that has directly tested this relationship between death type and realism. Although West et al. (2019) observed that the number of deaths players experienced differentiated PD games and what they labeled "faux-PD games" at the time, they did not elaborate on why that was one of the sole differences observed by PD/faux-PD players. It could be that the number of deaths players report experiencing while playing could lend themselves to the realism of players' gameplay perceptions, but future work would be needed to explore this claim. Another potential avenue for future PD research would be to test whether players might experience increased grief and MS immediately after dying in a PD game versus a PDRR game. By bringing in participants and experimentally manipulating what type of death they experienced in a lab and then assessing their reported levels of grief and MS shortly thereafter, researchers would not only be able to more accurately examine whether PD/temporary deaths differed in the amount of grief/MS they elicited, but they would also be able to use those findings to cross-validate whether players reported grief/MS differently immediately after experiencing the death compared to a short/long amount of time afterward (as was assessed in this study). Though player-reported grief may be lower in those experiments as players would have less time to become attached to their characters - which was an important factor in this study-further information exploring this complex PD phenomenon would only serve to aid researchers in understanding how PD impacts players in various capacities.

Future researchers could also examine how different coping styles might explain how players respond to permadeath temporary death experiences. Notably, this study only examined the role of people's predispositions to cope with adverse events through 
MM, but it did not examine how people actually did cope in response to their characters' deaths. It also did not measure for different coping styles that players might possess. It could be that rather than make meaning out of the deaths of their characters, players might engage in process of moral disengagement to help themselves cope. Hartmann and Vorderer (2010) observed that by undergoing moral disengagement (i.e., dehumanizing their characters, justifying violent actions), players' guilt and negative affect upon experiencing and enacting violence in video games decreased. In other words, by psychologically distancing themselves from their behaviors and from the deaths of their characters, these players were able to reduce the negative emotions they felt while playing violent games. Incorporating Hartmann and Vorderer's findings with those of this study's findings, it could be that players feel increased appreciation for their gameplay experiences through grief and MS because through other coping mechanisms, such as moral disengagement — rather than simply through MM — they are able to reduce their negative affect gained from their characters' deaths. Future work could more fully explore how different coping styles might facilitate this character death-appreciation relationship.

One final avenue for future research would be to examine what other motivations players might have for playing with PD. Although this dissertation made a particular point to explore the eudaimonic gratifications players might have and receive from playing PD games, it does not argue that they are the only reason these games hold appeal for some players. What other reasons might compel players to confront PDs particularly punishing nature? For instance, as players have been observed to like challenging games because they provide an enhanced sense of enjoyment (Petralito et al., 
2017), it might be that players are drawn to PD games because of the increased challenges they impose upon players by forcing them to better manage their resources (i.e., their characters and those characters' equipment, skills, and experience). With several motivations for playing video games already having been observed by previous researchers (Sherry et al., 2006; Yee, 2006), this final PD research path would simply involve applying those researchers' findings to PD players to help us better understand why players seek out PD experiences.

\section{Conclusion}

In the best way I can describe it, PD is a relatively unique gaming phenomenon wherein players give up one of their core freedoms provided by games (e.g., having an unlimited amount of second chances to play with little consequence), and they subject themselves to experiencing more punishing playstyles where they can potentially lose everything when their characters die...even the characters themselves. Inherently, this seems like a paradoxical way to play video games, and although players' decisions to self-select into experiencing PD might be explained by players being motivated by their need for challenge or competition (see Sherry et al., 2006; Yee, 2006), the findings in this dissertation indicate that players are likely more motivated to play PD games because they can garner an enhanced sense of appreciation through playing them. By allowing themselves to become increasingly attached to their characters, players also allow themselves to feel greater grief upon losing those characters, and inevitably, that grief then encourages these players to engage in reflection and contemplation of life's purpose and meaning, which increases their appreciation for the entire gameplay experience even more. Though it was not found that players might also be encouraged to contemplate 
their own deaths from playing PD games, individual death contemplation still led to increased appreciation for playing games in general. Ultimately, these experiences of grief and MS derived from playing games can become even more meaningful for players who might not normally engage in such reflection on a daily basis.

Taken as a whole, these findings provide just a small glimpse into some of the emotional and psychological benefits that games can offer players who are willing to engage with them. As the abilities and ingenuity of game developers continue to increase, it will be important that they continue to recognize that even just one small aspect of the gameplay experience (i.e., how characters die) can change the entirety of the experience for players as they grapple with the complex mechanics, narratives, and ideologies that will be presented to them. It will be exciting to see what the future of the gaming industry brings for the phenomenon of PD in video games.

1. As Cohen (2001) noted, it is important that identification should not be confused with various other constructs that have often conflated identification research. For instance, parasocial attachment and identification are different variables as identification refers to users literally "becoming one" with media figures whereas parasocial attachment refers to liking and feeling pseudo-interpersonally related to those figures (i.e., the difference being people perceiving one entity to exist or two). Identification should also be distinguished from wishful identification (i.e., wanting to be like a media figure; see Hoffner \& Buchanan, 2005) and similarity identification (Van Looy, Courtois, De Vocht, \& De Marez, 2010), as identification refers to users temporarily perceiving they have embodied the media figure, while wishful identification refers to users simply desiring that they were the figure and similarity identification is more akin to simple homophily than actual identity shifting.

2. Some players in this study $(5.1 \%)$ also reported on games that offered both customizable avatar characters as well as non-customizable agent characters (e.g., Divinity Original Sin II).

3. There were no CFAs run for the death theme accessibility measure or the Enjoyment and Appreciation 
Scale's appreciation subscale as (1) the death theme accessibility measure did not provide intervallevel data required to run a CFA, and (2) the appreciation subscale only contained 3 items, which does not meet the requirements to run a unidimensional CFA (see Bandalos, 2018).

4. For the sake of comparison, three other measures of PSR were assessed alongside Tukachinsky's (2010) Multiple PSR support subscale. Specifically, these measures were Rubin and Perse's (1987) 10item PSI scale, $r(392)=.572, p<.001$, Banks, Bowman, Lin, Pietschmann, and Wasserman's (2019; $r(392)=.666, p<.001) 4$-item "relational closeness" subscale of their cPAX scale, and Tukachinsky's $(2010 ; r(392)=.802, p<.001) 6$-item friendship communication subscale. The positive relationships between each of these scales and Tukachinsky's (2010) support subscale offer validation of the subscale's use to measure parasocial attachment in this study, and again, the primary purpose for selecting this subscale rather than the others was its overlap with how I conceptualized parasocial attachment for this study.

5. Several variables were also considered and measured as control variables for this study, namely participants' age, sex, player skill, total time spent with character, and the recency of the character's death before reporting. However, after inputting these variables as control variables in the main conditional process models, it was observed that they added minimal explanatory power to the study's models. Thus, for the sake of parsimony, these control variables were omitted from the final data analyses for this study.

6. Though the recall nature of participants' responses in this study is indeed a limitation, it is important to note that this method of data collection was still necessary to ensure several of the variables in this study were validly represented. It would, indeed, be possible to experimentally manipulate PDs vs temporary deaths in a lab setting (see "Future Direction 2"). However, one inherent drawback to this approach would be that players would likely not have the time needed to invest in their characters (see Rusbult, 1980; Rusbult et al., 2012) and to form parasocial attachments to them due to the artificial setting and process of research labs. Also, as expectations of future interactions are important for relationship development in computer-mediated settings (Walther, 1992), participants in such an experiment might also systematically resist becoming attached to these characters because they would know they would simply be leaving them behind as soon as the study was complete. Thus, for the 
intents of this study, it was necessary to allow players to respond to memorable PD and temporary death experiences so that sufficient variability in the character attachment variables was achieved for data analyses.

7. I do not mean to imply that the lack of CFA replication in communication research is simply the result of "lazy" research. Rather, I recognize there are numerous factors involved with performing and reporting tests of factor structures in manuscripts, such as overcoming publication biases from not obtaining the "right" results (see Schmidt \& Oh, 2016) or confronting page-limits imposed by journal editors and publishers. Nonetheless, this missing replication work is an important issue that contemporary researchers need to address. 


\section{References}

Abraham, B. (2013). Imposed rules and 'expansive gameplay': A close reading of the Far Cry 2 permadeath experiment. In Proceedings of the Digital Games Research Association Conference (pp. 26-29).

Allison, F., Carter, M., \& Gibbs, M. (2015). Good frustrations: The paradoxical pleasure of fearing death in DayZ. In Proceedings of the Meeting of the Australian Special Interest Group for Computer Human Interaction (pp. 119-123).

doi: $10.1145 / 2838739.2838810$

Anderson, B. (2015). Playing with death: The potential for violent video games to induce mortality salience (Masters thesis). Retrieved from https://soundideas.pugetsound.edu/cgi/viewcontent.cgi?article=1015\&context=ho nors_program_theses

Arndt, J., Greenberg, J., Pyszczynski, T., \& Solomon, S. (1997). Subliminal exposure to death-related stimuli increases defense of the cultural worldview. Psychological Science, 8, 379-385. doi:10.1111/j.1467-9280.1997.tb00429.x

Bandalos, D. L. (2018). Measurement theory and applications for the social science. New York, NY: Guilford.

Banks, J. (2015). Object, me, symbiote, other: A social typology of player-avatar relationships. First Monday, 20. doi:10.5210/fm.v20i2

Banks, J., \& Bowman, N. D. (2013). Close intimate playthings?: Understanding playeravatar relationships as a function of attachment, agency, and intimacy. Selected Papers in Internet Research, 3. Retrieved from http://spir.aoir.org/index.php/spir/article/view/689/pdf 
Banks, J., \& Bowman, N. D. (2016a). Avatars are (sometimes) people too: Linguistic indicators of parasocial and social ties in player-avatar relationships. New Media \& Society, 18, 1257-1276. doi:10.1177/1461444814554898

Banks, J., \& Bowman, N. D. (2016b). Emotion, anthropomorphism, realism, control: Validation of a merged metric for player-avatar interaction (PAX). Computers in Human Behavior, 54, 215-223. doi:10.1016/j.chb.2015.07.030

Banks, J., Bowman, N. D., Lin, J. H., Pietschmann, D., \& Wasserman, J. A. (2019). The common player-avatar interaction scale (cPAX): Expansion and cross-language validation. International Journal of Human-Computer Studies, 129, 64-73. doi:10.1016/j.jhhcs.2019.03.003

Bartle, R. A. (2004). Designing virtual worlds. Indianapolis, IN: New Riders.

Bartsch, A., Kalch, A., \& Oliver, M. B. (2014). Moved to think: The role of emotional media experiences in stimulating reflective thoughts. Journal of Media Psychology, 26, 125-140. doi:10.1027/1864-1105/a000118

Bounie, D., Bourreau, M., Gensollen, M., \& Waelbroeck, P. (2008). Do online customer reviews matter?: Evidence from the video game industry. Telecom Paris: Working Papers in Economics and Social Sciences. Retrieved from https://papers.ssrn.com/sol3/papers.cfm?abstract_id=1091449

Bowman, N. D., Oliver, M. B., Rogers, R., Sherrick, B., Woolley, J., \& Chung, M. (2016). In control or in their shoes?: How character attachment differentially influences video game enjoyment and appreciation. Journal of Gaming \& Virtual Worlds, 8, 83-99. doi:10.1386/jgvw.8.1.83_1

Brown, W. J. (2010). Steve Irwin's influence on wildlife conservation. Journal of 
Communication, 60, 73-93. doi:10.1111/j.1460-2466.2009.01458.x

Brown, W. J., Basil, M. D., \& Bocarnea, M. C. (2003). Social influence of an international celebrity: Responses to the death of Princess Diana. Journal of Communication, 53, 587-605. http://dx.doi.org/10.1111/j.14602466.2003.tb02912.x.

Burke, B. L., Martens, A., \& Faucher, E. H. (2009). Two decades of Terror Management Theory: A meta-analysis of mortality salience research. Personality and Social Psychology Review, 14, 155-195. doi:10.1177/1088868309352321

Carmack, H. J., \& LeFebvre, L. E. (2019). "Walking on eggshells": Traversing the emotional and meaning making processes surrounding hurtful course evaluations. Communication Education, 68, 350-370. doi:10.1080/03634523.2019.1608366

Carras, M. C., Kalbarczyk, A., Wells, K., Banks, J., Kowert, R., Gillespie, C., \& Latkin, C. (2018). Connection, meaning, and distraction: A qualitative study of video game play and mental health recovery in veterans treated for mental and/or behavioral health problems. Social Science \& Medicine, 216, 124-132. doi:10.1016/j.socscimed.2018.08.044

Carter, M., \& Allison, F. (2017). Fear, loss and meaningful play: Permadeath in DayZ. Journal of Gaming and Virtual Worlds, 9, 143-158. doi:10.1386/jgvw.9.2.143_1

Carver, C. S., \& Connor-Smith, J. (2010). Personality and Coping. Annual Review of Psychology, 61, 679-704. doi:10.1146/annurev.psych.093008.100352

Carver, C. S., Scheier, M. F., \& Weintraub, J. K. (1989). Assessing coping strategies: A theoretically based approach. Journal of Personality and Social Psychology, 56, 267-283. doi:10.1037//0022-3514.56.2.267 
Caserta, M., Lund, D., Utz, R. L., \& de Vries, B. (2009). Stress-related growth among the recently bereaved. Aging Mental Health 13, 463-476.

doi:10.1080/13607860802534641

Chang, A., Costantino, J., \& Soderman, B. (2017). The multiple lives of permadeath: An introduction. Journal of Gaming \& Virtual Worlds, 9, 103-121. doi:10.1386/jgvw.9.2.103_1

Chen, J. V., Lin, C., Yen. D. C., \& Linn, K-P. (2011). The interaction effects of familiarity, breadth, and media usage on web browsing experience. Computers in Human Behavior, 27, 2141-2152. doi:10.1016/j.chb.2011.06.008

Cheung, C. M. K., \& Lee., M. K. O. (2012). What drives consumers to spread electronic word of mouth in online consumer-opinion platforms. Decision Support Systems, 53, 218-225. doi:10.1016/j.dss.2012.01.015

Cohen, E. L., \& Hoffner, C. (2016). Finding meaning in a celebrity's death: The relationship between parasocial attachment, grief, and sharing educational health information related to Robin Williams on social network sites. Computers in Human Behavior, 65, 643-650. doi:10.1016/j.chb.2016.06.042

Cohen, J. (2001). Defining identification: A theoretical look at the identification of audiences with media characters. Mass Communication \& Society, 4, 245-264. doi:10.1207/S15327825MCS0403_01

Cohen, J. (2003). Parasocial breakups: measuring individual differences in responses to the dissolution of parasocial relationships. Mass Communication \& Society, 6, 191-202. doi:10.1207/S15327825MCS0602_5

Copcic, A., McKenzie, S., \& Hobbs, M. (2013, September). Permadeath: A review of 
literature. In Proceedings of the Games Innovation Conference, IEEE International (pp. 40-47). doi:10.1109/igic.2013.6659156

Coulson, M., Barnett, J., Ferguson, C. J., \& Gould, R. L. (2012). Real feelings for virtual people: Emotional attachments and interpersonal attraction in video games. Psychology of Popular Media Culture, 1, 176-184. doi:10.1037/a0028192

Daniel, E. S., \& Westerman, D. K. (2017). Valar Morghulis (all parasocial men must die): Having nonfictional responses to a fictional character. Communication Research Reports, 34, 143-152. doi:10.1080/08824096.2017.1285757

DeGroot, J. M., \& Leith, A. P. (2015). R.I.P. Kutner: Parasocial grief following the death of a television character. OMEGA—Journal of Death and Dying, 77, 199-216. doi: $10.1177 / 0030222815600450$

Dibble, J. L., Hartmann, T., \& Rosaen, S. F. (2016). Parasocial interaction and parasocial relationship: Conceptual clarification and a critical assessment of measures. Human Communication Research, 42, 21-44. doi:10.1111/hcre.12063

Eyal, K., \& Cohen, J. (2006). When good friends say goodbye: A parasocial breakup study. Journal of Broadcasting \& Electronic Media, 50, 502-523. doi:10.1207/s15506878jobem5003_9

Faschingbauer, T. R., Zisook, S., \& DeVaul, R. (1987). The Texas Revised Inventory of Grief. In S. Zisook (Ed.), Biopsychosocial aspects of bereavement (pp. 111-124). Washington, DC: American Psychiatric Press.

Folkman, S. (1997). Positive psychological states and coping with severe stress. Social Science \& Medicine, 45, 1207-1221. doi:10.1016/s0277-9536(97)00040-3

Folkman, S. (2008). The case for positive emotions in the stress process. Anxiety, Stress, 
\& Coping, 21, 3-14. doi:10.1080/10615800701740457

Gan, Y., Guo, M., \& Tong, J. (2013). Scale development of meaning-focused coping. Journal of Loss and Trauma, 18, 10-26. doi:10.1080/15325024.2012.678780

Gibson, M. (2017). Grievable lives: Avatars, memorials, and family 'plots' in Second Life. Mortality, 22, 224-239. doi:10.1080/13576275.2016.1263941

Goldberg, A. (1998). Avatars and agents, or life among the indigenous peoples of cyberspace. In C. Dodsworth (Ed.), Digital illusion: Entertaining the future with high technology (pp. 161-180). New York, NY: Addison-Wesley Publishing Company.

Goldenberg, J. L., \& Pyszczynski, T. (1999). The appeal of tragedy: A Terror Management perspective. Media Psychology, 1, 313-329. doi:10.1207/s1532785xmep0104_2

Goodboy, A. K., \& Kline. R. B. (2017). Statistical and practical concerns with published communication research featuring structural equation modeling. Communication Research Reports, 34, 68-77. doi:10.1080/08824096.2016.1214121

Gordon, R. (2016, October 25). 10 video game deaths we will never forget. GameRant. Retrieved from https://gamerant.com/top-video-game-death/

Greenberg, J., Pyszczynski, T., \& Solomon, S. (1986). The causes and consequences of a need for self-esteem: A Terror Management Theory. In R. F. Baumeister (Ed.), Public self and private self (pp. 189-212). New York: Springer-Verlag.

Greenberg, J., Pyszczynski, T., Solomon, S., Rosenblatt, A., Veeder, M., Kirkland, S., \& Lyon, D. (1990). Evidence for Terror Management Theory II: The effects of mortality salience on reactions to those who threaten or bolster the cultural 
worldview. Journal of Personality and Social Psychology, 58, 308-318. doi:10.1037//0022-3514.58.2.308

Greenberg, J., Pyszczynski, T., Solomon, S., Simon, L., \& Breus, M. (1994). Role of consciousness and accessibility of death-related thoughts in mortality salience effects. Journal of Personality and Social Psychology, 67, 627-637. doi:10.1037/0022-3514.67.4.627

Griffin, B. (2014, March 7). Why permadeath is alive and well in video games. gamesradar. Retrieved from https://www.gamesradar.com/why-permadeath-justwont-die-video-games/

Grodal, T. (2000). Video games and the pleasure of control. In D. Zillmann \& P. Vorderer (Eds.), Media entertainment: The psychology of its appeal (pp. 197213). Mahwah, NJ: Lawrence Erlbaum.

Grodal, T. (2007). Pain, sadness, aggression, and joy: An evolutionary approach to film emotions. Projections, 1, 91-107. doi:10:3167/proj.2007.010107

Groen, A. (2012, Nov. 27). In these games, death is forever, and that's awesome. Wired. Retrieved from: https://www.wired.com/2012/11/permadeath-dayz-xcom/

Harrer, S. (2013). From losing to loss: Exploring the expressive capacities of videogames beyond death as failure. Culture Unbound, 5, 607-620. doi:10.3384/cu.2000.1525.135607

Hartmann, T., \& Vorderer, P. (2010). It's okay to shoot a character: Moral disengagement in violent video games. Journal of Communication, 60, 94-119. doi:10.1111/j.1460-2466.2009.01459.x

Hayes, A. F. (2018a). Introduction to mediation, moderation, and conditional process 
analysis: A regression-based approach (2nd ed.). New York, NY: Guilford Press.

Hayes, A. F. (2018b). Partial, conditional, and moderated moderated mediation:

Quantification, inference, and interpretation. Communication Monographs, 85, 440. doi:10.1080/03637751.2017.1352100

Hayes, A. F., \& Rockwood, N. J. (2020). Conditional process analysis: Concepts, computation, and advances in the modeling of the contingencies of mechanism. American Behavioral Scientist, 64, 19-54. doi:10.1177/0002764219859633

Hernandez, M. D., \& Vicdan, H. (2014). Modeling word of mouth vs. media influence on videogame preorder decisions: A qualitative approach. Journal of Retailing and Consumer Services, 21, 401-406. doi:10.1016/j.jretconser.2013.11.003

Hofer, M. (2013). Appreciation and enjoyment of meaningful entertainment: The role of mortality salience and search for meaning in life. Journal of Media Psychology Theories Methods and Applications, 25, 109-117. doi:10.1027/1864$1105 / \mathrm{a} 000089$

Hoffner, C., \& Buchanan, M. (2005). Young adults' wishful identification with television characters: The role of perceived similarity and character attributes. Media Psychology, 7, 325-351. doi:10.1207/s1532785xmep0704_2

Holiman, J. M. (2013). iGrieve: Social media, parasocial mourning and the death of Steve Jobs (Master's Thesis). Retrieved from https://secure.suu.edu/hss/comm/masters/capstone/thesis/igrieve-holiman-j.pdf

Hong, Y. Y., Wong, R. Y. M., \& Liu, J. H. (2001). The history of war strengthens ethnic identification. Journal of Psychology in Chinese Societies, 2, 77-105. Retrieved from 
https://www.researchgate.net/publication/337830395_Hong_Y_Wong_R_Y_M_L iu_J_H_2001_The_history_of_war_strengthens_ethnic_identification

Horton, D., \& Strauss, A. (1957). Interaction in audience-participation shows. American Journal of Sociology, 62, 579-587. doi:10.1086/222106

Horton, D., \& Wohl, R. R. (1956). Mass communication and para-social interaction. Psychiatry, 19, 215-229. doi:10.1080/00332747.1956.11023049

Hutchinson, L. (2013, May 5). The simple lesson I learned from 369 hours of Mass Effect. ars technica. Retrieved from https://arstechnica.com/gaming/2013/05/thesimple-lesson-i-learned-from-369-hours-of-mass-effect/

Jansz, J. (2005). The emotional appeal of violent video games for adolescent males. Communication Theory, 15, 219-241. doi:10.1093/ct/15.3.219

Jennings, N., \& Alper, M. (2016). Young children's positive and negative parasocial relationships with media characters. Communication Research Reports, 33, 96102. doi:10.1080/08824096.2016.1154833

Jones, C. M., Scholes, L., Johnson, D., Katsikitis, M., \& Carras, M. C. (2014). Gaming well: Links between videogames and flourishing mental health. Frontiers in Psychology, 5, 1-8. doi:10.3389/fpsyg.2014.00260

Juhl, J., \& Routledge, C. (2016). Putting the terror in Terror Management Theory: Evidence that the awareness of death does cause anxiety and undermine psychological well-being. Current Directions in Psychological Science, 25, 99103. doi:10.1177/0963721415625218

Kaplan, R. L., Levine, L. J., Lench, H. C., \& Safer, M. A. (2015). Forgetting feelings: Opposite biases in reports of the intensity of past emotion and mood. Emotion, 16, 
309-319. doi:10.1037/emo0000127

Kehl, K. A. (2006). Moving toward peace: An analysis of the concept of a good death. American Journal of Hospice \& Palliative Medicine, 23, 277-286. doi: $10.1177 / 1049909106290380$

Kelly, S. (2012). Dead bodies that matter: Toward a new ecology of human death in American culture. The Journal of American Culture, 35, 37-51. doi:10.1111/j.1542-734x.2011.00796.x

Keogh, B. (2013, September). When game over means game over: Using permanent death to craft living stories in Minecraft. In Proceedings of The 9th Australasian Conference on Interactive Entertainment: Matters of Life and Death (pp. 20-26). doi:10.1145/2513002.2513572

Kim, J., \& Song, H. (2016). Celebrity's self-disclosure on Twitter and parasocial relationships: A mediating role of social presence. Computers in Human Behavior, 62, 570-577. doi:10.1016/j.chb.2016.03.083

Klastrup, L. (2008). What makes World of Warcraft a world?: A note on death and dying. In H. G. Corneliussen \& J. W. Rettberg (Eds.), Digital culture, play, and identity: A World of Warcraft reader (pp. 143-166). Cambridge, MA: MIT Press.

Kleinman, Z. (2019, April 29). Minecraft player loses five-year-long game. $B B C$. Retrieved from https://www.bbc.com/news/technology-48091843

Klimmt, C. (2011). Media psychology and complex modes of entertainment experiences. Journal of Media Psychology, 23, 34-38. doi:10.1027/1864-1105/a000030

Klimmt, C., Hefner, D., \& Vorderer, P. (2009). The video game experience as "True" identification: A theory of enjoyable alterations of players' self-perception. 
Communication Theory, 19, 351-373. doi:10.1111/j.1468-2885.2009.01347.x

Klimmt, C., Hefner, D., Vorderer, P., Roth, C., \& Blake, C. (2010). Identification with video game characters as automatic shift of self-perceptions. Media Psychology, 13, 323-338. doi:10.1080/15213269.2010.524911

Kline, R. B. (2016). Principles and practice of structural equation modeling $\left(4^{\text {th }} \mathrm{ed}\right.$.). New York, NY: Guilford.

Knobloch, S., \& Zillmann, D. (2002). Mood management via the digital jukebox. Journal of Communication, 52, 351-366. doi:10.1111/j.1460-2466.2002.tb02549.x

Knobloch-Westerwick, S., \& Alter, S. (2006). Mood adjustment to social situations through mass media use: How men ruminate and women dissipate angry moods. Human Communication Research, 32, 58-73. doi:10.1111/j.14682958.2006.00003.x

Knobloch-Westerwick, S., Gong, Y., Hagner, H., \& Kerbeykian, L. (2012). Tragedy viewers count their blessings: Feeling low on fiction leads to feeling high on life. Communication Research, 40, 747-766. doi:10.1177/0093650212437758

Koopman, E. M. (2015). Why do we read sad books?: Eudaimonic motives and metaemotions. Poetics, 52, 18-31. doi:10.1016/j.poetic.2015.06.004

Kübler-Ross, E. (1969). On death and dying. New York: NY: Macmillan Company. Kumagai, T., \& Ohbuchi, K. (2003). The effect of mortality salience and collaborative experience on aggression of "third-party victims". Tohoku Psychologica Folia, 62, 109-119. Retrieved from https://tohoku.repo.nii.ac.jp/?action=pages_view_main\&active_action=repository _view_main_item_detail\&item_id=1485\&item_no=1\&page_id=33\&block_id=38 
Landau, M. J., Solomon, S., Greenberg, J., Cohen, F., Pyszczynski, T., Arndt, J., ... Cook, A. (2004). Deliver us from evil: The effects of mortality salience and reminders of 9/11 on support for President George W. Bush. Personality and Social Psychology Bulletin, 30, 1136-1150. doi:10.1177/0146167204267988

Lewis, R. J., Tamborini, R., \& Weber, R. (2014). Testing a dual-process model of media enjoyment and appreciation. Journal of Communication, 64, 397-416. doi:10.1111/jcom.12101

Lewis, M. L., Weber, R., \& Bowman, N. D. (2008). “They may be pixels, but they're my pixels:" Developing a metric of character attachment in role-playing video games. CyberPsychology \& Behavior, 11, 515-518. doi:10.1089/cpb.2007.0137

Lombard, M., \& Ditton, T. (1997). At the heart of it all: The concept of presence. Journal of Computer-Mediated Communication, 3. doi:10.1111/j.1083-6101.1997.tb00072.x

Lynch, T., \& Matthews, N. L. (2017). Life \& death: The meaning of (digital) existence. In J. Banks (Ed.), Avatar, assembled: The social and technical anatomy of digital bodies (pp. 13-21). New York, NY: Peter Lang.

Matthews, N. L. (2015). Too good to care: The effect of skill on hostility and aggression following violent video game play. Computers in Human Behavior, 48, 219-225. doi:10.1016/j.chb.2015.01.059

McDonald, R. P. (1999). Test theory: A unified treatment. Mahwah, NJ: Erlbaum.

Meier, E. A., Gallegos, J. V., Montross-Thomas, L. P., Depp, C. A., Irwin, S. A., \& Jeste, D. V. (2016). Defining a good death (successful dying): Literature review and a call for research and public dialogue. Am J Geriatr Psychiatry, 24, 261-271. 
doi:10.1016/j.jagp.2016.01.135

Meij, L. W., Stroebe, M., Schut, H., Stroebe, W., van den Bout, J., Heijden, P. V. D., \& Dijkstra, I. (2005). Couples at risk following the death of their child: Predictors of grief versus depression. Journal of Consulting and Clinical Psychology, 73, 617623. doi:10.1037/0022-006X.73.4.617

Melnic, D., \& Melnic, V. (2018). Saved games and respawn timers: The dilemma of representing death in video games. University of Bucharest Review, 7, 29-37. Retrieved from https://www.researchgate.net/profile/Diana_Melnic/publication/327136668_Save d_games_and_respawn_timers_The_dilemma_of_representing_death_in_video_g ames/links/5b7bd26f4585151fd1240dc2/Saved-games-and-respawn-timers-Thedilemma-of-representing-death-in-video-games.pdf

Moyer-Gusé, E., Chung, A. H., \& Jain, P. (2011). Identification with characters and discussion of taboo topics after exposure to an entertainment narrative about sexual health. Journal of Communication, 61, 387-406. doi:10.1111/j.14602466.2011.01551.x

Myrick, J. G. (2015). Emotion regulation, procrastination, and watching cat videos online: Who watches Internet cats, why, and to what effect?. Computers in Human Behavior, 52, 168-176. doi:10.1016/j.chb.2015.06.001

Nelson, L. J., Moore, D. L., Olivetti, J., \& Scott, T. (1997). General and personal mortality salience and nationalistic bias. Personality and Social Psychology Bulletin, 23, 884-892. doi:10.1177/0146167297238008

Oliver, M. B. (1993). Exploring the paradox of the enjoyment of sad films. Human 
Communication Research, 19, 315-342. doi:10.1111/j.1468-2958.1993.tb00304.x

Oliver, M. B. (2008). Tender affective states as predictors of entertainment preference. Journal of Communication, 58, 40-61. doi:10.1111/j.1460-2466.2007.00373.x

Oliver, M. B., \& Bartsch, A. (2010). Appreciation as audience response: Exploring entertainment gratifications beyond hedonism. Human Communication Research, 36, 53-81. doi:10.1111/j.1468-2958.2009.01368.x

Oliver, M. B., \& Bartsch, A. (2011). Appreciation of entertainment: The importance of meaningfulness via virtue and wisdom. Journal of Media Psychology, 23, 29-33. doi:10.1027/1864-1105/a000029

Oliver, M. B., Bowman, N. D., Woolley, J. K., Rogers, R., Sherrick, B. I., \& Chung, M. (2015). Video games as meaningful entertainment. Psychology of Popular Media and Culture, 5, 390-405. doi:10.1037/ppm0000066

Oliver, M. B., \& Hartmann, T. (2010). Exploring the role of meaningful experiences in users' appreciation of “good movies”. Projections, 4, 128-150. doi:10.3167/proj.2010.040208

Oliver, M. B., \& Raney, A. A. (2011). Entertainment as pleasurable and meaningful: Identifying hedonic and eudaimonic motivations for entertainment consumption. Journal of Communication, 61, 984-1004. doi:10.1111/j.1460-2466.2011.01585.x

Oliver, M. B., Raney, A. A., Slater, M. D., Appel, M., Hartmann, T., Bartsch, A., ... Das, E. (2018). Self-transcendent media experiences: Taking meaningful media to a higher level. Journal of Communication, 68, 380-389. doi:10.1093/joc/jqx020

Park, C. L. (2010). Making sense of the meaning literature: An integrative review of meaning making and its effects on adjustment to stressful life events. 
Psychological Bulletin, 136, 257-301. doi:10.1037/a0018301

Parker, R. (2017). The culture of permadeath: Roguelikes and terror management theory. Journal of Gaming \& Virtual Worlds, 9, 123-141. doi:10.1386/jgvw.9.2.123_1

Perloff, R. M. (2016). An integrative Terror Management Theory perspective on media effects: A model and 12 hypotheses for research. Studies in Media and Communication, 4, 49-62. doi:10.11114/smc.v4i1.1600

Petralito, S., Brühlmann, F., Iten, G., Mekler, E. D., Opwis, K. (2017). A good reason to die: How avatar death and high challenges enable positive experiences. Paper presented at the meeting of the International Conference on Human factors in Computing Systems. Denver, CO: ACM Press. doi:10.1145/3025453.3026047

Pihlström, S. (2015). Controlling death: Philosophical thanatology meets pragmatism. Mortality, 20, 48-66. doi:10.1080/13576275.2014.966068

Pinchefsky, C. (2013, January 11). Why do gamers play one game for hundreds, even thousands of hours? Forbes. Retrieved from https://www.forbes.com/sites/carolpinchefsky/2013/01/11/why-do-gamers-playone-game-for-hundreds-even-thousands-of-hours/\#40d81ec87638

Przybylski, A. K., Rigby, C. S., \& Ryan, R. M. (2010). A motivational model of video game engagement. Review of General Psychology, 14, 154-166. doi:10.1037/a0019440

Radford, S. K., \& Bloch, P. H. (2013). Consumers' online responses to the death of a celebrity. Marketing Letters, 24, 43-55. http://dx.doi.org/10.1007/s11002-012$9202-5$

Raney, A. A., Oliver, M. B., \& Bartsch, A. (2019). Eudaimonia as media effect. In M. B. 
Oliver, A. A. Raney, \& J. Bryant (Eds.), Media effects: Advances in theory and research ( $4^{\text {th }}$ ed., pp. 258-274). New York, NY: Routledge.

Reinecke, L. (2009). Games and recovery: The use of video and computer games to recuperate from stress and strain. Journal of Media Psychology, 21, 126-142. doi:10.1027/1864-1105.21.3.126

Reinecke, L. (2017). Mood Management Theory. The International Encyclopedia of Media Effects, 1-13. doi:10.1002/9781118783764.wbieme0085

Reinecke, L., Hartmann, T., \& Eden, A. (2014). The guilty couch potato: The role of ego depletion in reducing recovery through media use. Journal of Communication, 64, 569-589. doi:10.1111/jcom.12107

Rieger, D. (2017). Meaning, mortality salience, and media use. In L. Reinecke \& M. B. Oliver (Eds.), The Routledge handbook of media use and well-being: International perspectives on theory and research on positive media effects (93105). New York, NY: Routledge.

Rieger, D., Frischlich, L., Högden, F., Kauf, R., Schramm, K., \& Tappe, E. (2015). Appreciation in the face of death: Meaningful films buffer against death-related anxiety. Journal of Communication, 65, 351-372. doi:10.1111/jcom.12152

Rigby, C. S., \& Ryan, R. M. (2016). Time well-spent?: Motivation for entertainment media and is eudaimonic aspects through the lens of self-determination theory. In L. Reinecke \& M. B. Oliver (Eds.), The Routledge handbook of media use and well-being: International perspectives on theory and research on positive media effects (pp. 34-48). New York, NY: Routledge.

Rosaen, S. F., \& Dibble, J. L. (2008). Investigating the relationships among child's age, 
parasocial interactions, and the social realism of favorite television characters. Communication Research Reports, 25, 145-154.

doi:10.1080/08824090802021806

Rosaen, S. F., \& Dibble, J. L. (2017). The impact of viewer perceptions of media personae and viewer characteristics on the strength, enjoyment, and satisfaction of parasocial relationships. Communication Studies, 68, 1-21. doi:10.1080/10510974.2016.1240701

Rosenblatt, A., Greenberg, J., Solomon, S., Pyszczynski, T., \& Lyon, D. (1989). Evidence for Terror Management Theory: I.: The effects of mortality salience on reactions to those who violate or uphold cultural values. Journal of Personality and Social Psychology, 57, 681-690. doi:10.1037/0022-3514.57.4.681

Rousse, T. (2011, December 19). On permadeath. SSRN. Retrieved from https://ssrn.com/abstract=2001550

Routledge, C., Arndt, J., \& Goldenberg, J. L. (2004). A time to tan: Proximal and distal effects of mortality salience on sun exposure intentions. Personality and Social Psychology Bulletin, 30, 1347-1358. doi:10.1177/0146167204264056

Routledge, C., Ostafin, B., Juhl, J., Sedikides, C., Cathey, C., \& Liao, J. (2010). Adjusting to death: The effects of mortality salience and self-esteem on psychological well-being, growth motivation, and maladaptive behavior. Journal of Personality and Social Psychology, 99, 897-916. doi:10.1037/a0021431

Rusbult, C. E. (1980). Commitment and satisfaction in romantic associations: A test of the Investment Model. Journal of Experimental Social Psychology, 16, 172-186. doi:10.1016/0022-1031(80)90007-4 
Rusbult, C. E., Agnew, C. R., \& Arriaga, X. B. (2012). The investment model of commitment processes. In P. A. M. Van Lange, A. W. Kruglanski, \& E. T. Higgins (Eds.), The handbook of theories of social psychology (Vol. 2, pp. 218231). Thousand Oaks, CA: SAGE.

Russo, M. D. (2016, April 23). 10 most heartbreaking video game deaths of all time. ScreenRant. Retrieved from https://screenrant.com/best-most-heartbreakingvideo-game-deaths-ever-all-time/

Russoniello, C. V., O’Brien, K., \& Parks, J. M. (2009). The effectiveness of casual video games in improving mood and decreasing stress. Journal of CyberTherapy \& Rehabilitation, 2, 53-66. Retrieved from https://www.researchgate.net/profile/Carmen_Russoniello/publication/289131468 _The_effectiveness_of_casual_video_games_in_improving_mood_and_decreasin g_stress/links/589b371492851c942ddac68d/The-effectiveness-of-casual-videogames-in-improving-mood-and-decreasing-stress.pdf

Ryan, R. M., Rigby, C. S., \& Przybylski, A. (2006). The motivational pull of video games: A Self-Determination Theory approach. Motivation and Emotion, 30, 344360. doi:10.1007/s11031-006-9051-8

Sanderson, J., \& Cheong, P. H. (2010). Tweeting prayers and communicating grief over Michael Jackson online. Bulletin of Science, Technology, \& Society, 30, 328-340. doi: $10.1177 / 0270467610380010$

Schmidt, F. L., \& Oh. I.-S. (2016). The crisis of confidence in research findings in psychology: Is lack of replication the real problem?: Or is it something else?. Archives of Scientific Psychology 4, 32-37. doi:10.1037/arc0000029 
Schutter, B. D., \& Brown, J. A. (2015). Digital games as a source of enjoyment in later life. Games and Culture, 11, 1-25. doi:10.1177/1555412015594273

Semin, G., R., \& Smith. E. R. (1999). Revisiting the past and back to the future: Memory systems and the linguistic representation of social events. Attitudes and Social Cognition, 76, 877-892. doi:10.1037/0022-3514.76.6.877

Senior, T. (2019, May 3). The most crushing videogame deaths. PC Gamer. Retrieved from https://www.pcgamer.com/the-most-crushing-videogame-deaths/

Sherry, J. L., Lucas, K., Greenberg, B. S., \& Lachlan, K. (2006). Video game uses and gratifications as predictors of use and game preference. In P. Vorderer \& J. Bryant (Eds.), Playing computer games: Motives, responses, and consequences (pp. 213224). Mahwah, NJ: Lawrence Erlbaum.

Slater, M. D., Oliver, M. B., \& Appel, M. (2016). Poignancy and mediated wisdom of experience: Narrative impacts on willingness to accept delayed rewards. Communication Research, 46, 333-354. doi:10.1177/0093650215623838

Solomon, S., Greenberg, J., \& Pyszczynski, T. (1991). A Terror Management Theory of social behavior: The psychological functions of self-esteem and cultural worldviews. Advances in Experimental Social Psychology, 24, 93-159. doi:10.1016/s0065-2601(08)60328-7

Song, W., \& Fox, J. (2016). Playing for love in a romantic video game: Avatar identification, parasocial relationships, and Chinese women's romantic beliefs. Mass Communication and Society, 19, 197-215.

doi:10.1080/15205436.2015.1077972

Tamborini, R., Bowman, N. D., Eden, A., Grizzard, M., \& Organ, A. (2010). Defining 
media enjoyment as the satisfaction of intrinsic needs. Journal of Communication, 60, 758-777. doi:10.1111/j.1460-2466.2010.01513.x

Tamborini, R., Grizzard, M., Bowman, N. D., Reinecke, L., Lewis, R. J., \& Eden, A. (2011). Media enjoyment as need satisfaction: The contribution of hedonic and nonhedonic needs. Journal of Communication, 61, 1025-1045. doi:10.1111/j.1460-2466.2011.01593.x

Tan, K., Agnew, C. R., VanderDrift, L. E., \& Harvey, S. M. (2015). Committed to us: Predicting relationship closeness following nonmarital romantic relationship breakup. Journal of Social and Personal Relationships, 32, 456-471. doi: $10.1177 / 0265407514536293$

Tomita, T., \& Kitamura, T. (2002). Clinical and research measures of grief: A reconsideration. Comprehensive Psychiatry, 43, 95-102. doi:10.1053/comp.2002.30801

Trope, Y., \& Liberman, N. (2010). Construal-Level Theory of psychological distance. Psychological Review, 117, 440-463. doi:10.1037/a0018963

Tsay, M., Krakowiak, M. K., \& Oliver, M. B. (2012, May). Exploring the impact of cognitively challenging content on mortality salience. Paper presented at the meeting of the International Communication Association, Phoenix, AZ.

Utz, R. L., Caserta, M., \& Lund, D. (2011). Grief, depressive symptoms, and physical health among recently bereaved spouses. The Gerontologist, 52, 460-471. doi:10.1093/geront/gnr110

van den Hoogen, W. V. D., Poels, K., Ijsselsteijn, W., \& Kort, Y. D. (2012). Between challenge and defeat: Repeated player-death and game enjoyment. Media 
Psychology, 15, 443-459. doi:10.1080/15213269.2012.723117

Van Looy, J., Courtois, C., De Vocht, M., \& De Marez, L. (2012). Player identification in online games: Validation of a scale for measuring identification in MMOGs. Media Psychology, 15, 197-221. doi:10.1080/15213269.2012.674917

Vorderer, P., Klimmt, C., \& Ritterfeld, U. (2004). Enjoyment: At the heart of media entertainment. Communication Theory, 14, 388-408. doi:10.1111/j.14682885.2004.tb00321.x

Vorderer, P., \& Reinecke, L. (2015). From mood to meaning: The changing model of the user in entertainment research. Communication Theory, 25, 447-453. doi:10.1111/comt.12082

Walther, J. B. (1992). Interpersonal effects in computer-mediated interaction: A relational perspective. Communication Research, 19, 52-90.

doi:10.1177/009365092019001003

Wanzer, M., Booth-Butterfield, M., \& Booth-Butterfield, S. (2005). "If we didn't use humor, we'd cry": Humorous coping communication in health care settings. Journal of Health Communication, 10, 105-125. doi:10.1080/10810730590915092

Waterman, A. S. (1993). Two conceptions of happiness: Contrasts of personal expressiveness (eudaimonia) and hedonic enjoyment. Journal of Personality and Social Psychology, 64, 678-691. doi:10.1037//0022-3514.64.4.678

Watts, E. R., West, M. S., \& Bowman, N. D. (2018, November). The role of video game critics in video game taste cultures. Paper presented at the meeting of the National Communication Association, Salt Lake City, UT. 
West, M. S., Bowman, N. D., \& Cohen, E. L. (2019). Examining players' permadeath experiences through player-avatar relationships and video game demands. Unpublished manuscript, Department of Communication Studies, West Virginia University, Morgantown, West Virginia.

Williams-Murphy, M. (2012, October 18). What is a "bad death" and how can it be avoided?. oktodie. Retrieved from http://www.oktodie.com/blog/what-is-a-baddeath-and-how-can-it-beavoided/?fbclid=IwAR21_LLyuXO_MmcqDVK25dVqJVi8iwB28Fd4_qo7KR0Q 2trLzypTpipsRnM

Wirth, W., Hofer, M., \& Schramm, H. (2012). Beyond pleasure: Exploring the eudaimonic entertainment experience. Human Communication Research, 38, 406428. doi:10.1111/j.1468-2958.2012.01434.x

Wirth, W., Ryffel, F., von Pape, T., \& Karnowski, V. (2013). The development of video game enjoyment in a role playing game. CyberPsychology, Behavior, and Social Networking, 16, 260-264. doi:10.1089/cyber.2012.0159

White, D. J., \& Grossfeld, M. L. (2012). Irrevocability in games. Retrieved from https://digitalcommons.wpi.edu/iqpall/2947?utm_source=digitalcommons.wpi.edu\%2Fiqpall\%2F2947\&utm_medium=PDF\&utm_campaign=PDFCoverPages

Yee, N. (2006). Motivations for play in online games. CyberPsychology \& Behavior, 9, 772-775. doi:10.1089/cpb.2006.9.772

Zillmann, D. (1988). Mood management through communication choices. The American Behavioral Scientist, 31, 327-340. doi:10.1177/000276488031003005 
Appendix A

\section{Reddit Recruitment Post}

Recruitment Post Title: Seeking Player Responses to a Research Survey about Experiencing Character "Death" in Gaming: My Dissertation

Hello players,

I am a doctoral student in West Virginia University's Department of Communication Studies. You are invited to participate in a research study (my dissertation, actually) about death in gaming.

The purpose of this research is to learn more about how players respond when their video game characters die. I want to hear your personal stories, feelings and thoughts about witnessing the death of one of your game characters.

This questionnaire is available online. It will take approximately 25 minutes to complete. Your answers to the questions, and your involvement in the study, will be kept confidential.

After completing the questionnaire, you can choose to be entered in a drawing to possibly win a $\$ 100$ gift card for Amazon.com (8 total gift cards will be drawn).

To be eligible to participate in this research you must meet 3 requirements:

1. You must have played at least one role-playing game with permadeath (e.g., XCOM 2 , The Sims 4) in the previous year and experienced the permanent death of a game character. For the purposes of this study, I define permadeath as a game mechanic in which characters who lose all their health effectively die, and cannot be used anymore in subsequent play attempts.

2. You must have played at least one role-playing game in which you experienced the temporary death of a character (i.e., the death was not permanent). In other words, after the character died you were able to start over and reuse the character in subsequent play attempts (e.g., The Witcher 3, The Outer Worlds).

3. You must be at least 18 years of age.

Participation in this research is offered on a first-come, first-serve basis. I hope to enroll approximately 400 video game players in this research. Once a sufficient number of responses have been collected, I will close the study and prevent further participation.

This study has been acknowledged by West Virginia University's Institutional Review Board, and is on file as Protocol \#1912835407. 
Thank you for taking the time to read through this post!

If you have any questions or concerns, please e-mail me, Mckay Steven West (msw0020@mix.wvu.edu).

Or you can contact my research supervisor, Dr. Elizabeth Cohen, Associate Professor of Communication Studies (elizabeth.cohen@mail.wvu.edu).

If you wish to participate in this study, please visit the link below to learn the complete details of the study and to fill out the survey:

https://wvu.qualtrics.com/jfe/form/SV_5z2Ve4iDZ9JUesR 


\section{Appendix B}

\section{Consent Information Page}

\author{
Principal Investigator (PI) \\ Department \\ WVU IRB Protocol \# \\ Study Title
}

Elizabeth L. Cohen (Elizabeth.Cohen@mail.wvu.edu)

Communication Studies, West Virginia University

1912835407

Studying Death in Gaming

\section{Why is this research being done and what is involved?}

Dear Participant,

You are invited to participate in a research study conducted by Mckay Steven West and Elizabeth L. Cohen from the Department of Communication Studies at West Virginia University. The purpose of this study is to increase our knowledge of players' reactions to death in gaming.

You will be asked to describe several aspects of your gaming experience, particularly on the topic of character deaths in gaming. It should take approximately 25 minutes to complete this study.

We ask that you please complete this questionnaire on a laptop or desktop as there are portions of the questionnaire that will involve typing.

\section{Do I have to participate and what are the risks?}

Your participation in this research study is completely voluntary and you are free to withdraw from the research at any time. You may or may not directly benefit from participating in this research. There are no known risks associated with participation in this study.

\section{Will I be compensated for my participation?}

By completing this study, you will be eligible to enter a drawing for 1 of 8 gift cards ( $\$ 100$ each) for Amazon.com. You must complete the study in its entirety to be eligible for this drawing. You will be required to provide a working email address at the end of the study if you wish to enter this drawing.

Your information, if obtained, may be provided to the appropriate parties for billing and/or payment purposes. Please be advised that any compensation received for participation in a research study, including a gift card, is considered taxable income and must be reported to the Internal Revenue Service (IRS). Your email will not be used for any other purposes.

Your data, health information, research results, specimens, or any and all other information related to this research study used in this research study may contribute to a new discovery or treatment. In some instances, your data, your health information, your research results, your specimens, these discoveries or treatments, or any other information related to this research study, even if identifiers are removed, may be of commercial value and may be sold, patented, or licensed by the investigators and West Virginia University for use in other research or the development of new products. You will not retain any property rights, nor will you share in any money or commercial profit that the investigators, West Virginia University, or their agents may realize. 


\section{What will happen to my research information and data?}

Any information about you that is obtained as a result of your participation in this research will be kept as confidential as legally possible. Your responses to this questionnaire, just like hospital records, may be subpoenaed by court order or may be inspected by the study sponsor or federal regulatory authorities without your additional consent.

In addition, there are certain instances where the researcher is legally required to give information to the appropriate authorities. These would include mandatory reporting of infectious diseases, mandatory reporting of information about behavior that is imminently dangerous to you or to others, such as suicide, child abuse, etc.

In any publications that result from this research, neither your name nor any information from which you might be identified will be published without your consent.

\section{Who can I talk to if I have questions or concerns?}

If you have any questions or concerns about this research, you can contact Mckay Steven West at msw0020@mix.wvu.edu from the Department of Communication Studies at West Virginia University. You may also contact the study's PI, Elizabeth L. Cohen, at Elizabeth.Cohen@mail.wvu.edu if desired.

For information regarding your rights as a participant in research or to talk about the research, contact the WVU Office of Human Research Protection (OHRP) at (304) 293-7073 or by email (IRB@mail.wvu.edu).

Please click the "Next" button if you agree to the above terms and conditions. 


\section{Appendix C}

Survey Instrument

\section{I. $\quad$ Screening}

Thank you again for being willing to participate today! To start off, we have a couple of questions about your video game playing experiences in the past year.

At any time during the past year did you experience the permanent death of a game character in a role-playing game that utilized a permadeath mechanic? For the purposes of this research, permadeath occurs when characters who lose all their health effectively die, and cannot be used anymore in subsequent play attempts.

In other words, have you lost a game character that you were NOT able to resurrect later? For the intents of this study, please only answer "Yes" if you did not cheat in any way to bring this character back to life (i.e., you did not manipulate save file data to prevent losing your character).

Yes/No

If "No": Direct to end of survey.

If "Yes":

What was the name of the game in which you had this permadeath experience? If you had this experience with multiple games, please pick the game where you had the permadeath experience that you can remember most easily. Please list the name of the game where you had your most memorable experience.

What was the name of the character who suffered the permadeath in this game?

Please estimate how long ago it was that the permadeath you referenced occurred.

1 - Very Recently (Within the past few weeks)

2 - Fairly Recently (Within the past few months)

3 - A Little While Ago (Several months ago)

4 - A Long While Ago (Nearly a year ago)

At any time during the past year did you experience the temporary death of a game character in a role-playing game? In other words, have you lost a game character that you were able to resurrect and play with again later?

Note. You do not need to have cheated or manipulated save file data for the death to be considered temporary. In cases where a character simply revives at a previous checkpoint, respawns away from the death location, or you restart a mission with them are also considered temporary deaths. 
Yes/No

If "No": Direct to end of survey.

If "Yes":

What was the name of the game in which you had this temporary character death experience? If you had this experience with multiple games, please pick the game where you had the temporary death experience that you can remember most easily. Please list the name of the game where you had your most memorable experience.

What type of genre would you say best represents this game?

1 - Role-playing Game

2 - Action

3 - Sports

4 - Strategy

5 - Multiplayer Online Battle Arena (MOBA)

6 - Massively Multiplayer Online (MMO)

7 - Platformer

8 - Fighting

9 - Simulation

10 - Battle Royale

What was the name of the character who suffered the temporary death in this game?

Please estimate how long ago it was that the permadeath you referenced occurred.

1 - Very Recently (Within the past few weeks)

2 - Fairly Recently (Within the past few months)

3 - A Little While Ago (Several months ago)

4 - A Long While Ago (Nearly a year ago)

\section{[PAGE BREAK]}

\section{Character Descriptions}

As you may recall, this study seeks to learn more about the experiences players have with character deaths. For this reason, we would like to hear more about your specific experiences with your character death.

For this next set of questions, please think about the permadeath/temporary death experience that you reported on in the last section. To remain consistent, please use the 
same character death experience to answer all questions throughout the study.

To begin, please give us a little bit more information about the character who suffered the permanent/temporary death.

Approximately, how long had you played with [piped text] prior to [piped text]'s death? In other words, how long did you spend playing as [piped text] before the death you are thinking of happened?

Please fill in the blanks below with your best estimate of the total time you spent with [piped text]. For instance, if you played with [piped text] for 2 and a half months, you would fill in: "0 Years, 2 Months, 2 Weeks, 0 Days, 0 Hours, 0 Minutes."

_Years __Months __Weeks __Days __Hours __Minutes

Around the time that [piped text] died, about how frequently were you playing [piped text]?

1- Rarely (Less than every two weeks)

2- Occasionally (Every week or two)

3- Somewhat Regularly (Once a week)

4- Regularly (A few days a week)

5- Often (Once daily)

6- Extremely Often (Several times a day)

\section{[PAGE BREAK]}

Now, we are very interested in learning more about [piped text].

For the next few minutes, please describe [piped text] in as much detail as you can. Here are some questions you may consider answering: Did you design [piped text]? If so, why did you design [piped text] like you did? What did [piped text] look like? How old was [piped text]? What was [piped text] like? What did you like about [piped text]? What did you dislike about [piped text]? How did you feel about [piped text]?

Any information you can provide about [piped text] would be helpful and much appreciated.

\section{[PAGE BREAK]}

\section{Character Attachments}

Now, we'd like to you to please try to remember how you felt about [piped text] PRIOR to his/her death you reported. Please read the statements below and indicate how much 
you agree with them on a scale from 1 (Strongly Disagree) to 7 (Strongly Agree).

Revised Parasocial Interaction Scale [adapted from Rubin \& Perse, 1987]

$(1=$ Strongly Disagree; 7 = Strongly Agree $)$

1. While playing [piped text], [piped text] made me feel comfortable, as if I was with a friend.

2. I saw [piped text] as a natural, down-to-earth person.

3. I looked forward to playing with [piped text].

4. If [piped text] appeared in another game, I would play that game.

5. [piped text] seemed to understand the kinds of things I wanted to know.

6. If I saw a story about [piped text] in a newspaper or magazine, I would read it.

7. I missed seeing [piped text] when I was not playing with him/her.

8. If [piped text] were real, I would have liked to meet him/her in person.

9. I felt sorry for [piped text] when he/she made mistakes.

10. I find [piped text] to be attractive.

Multiple PSR Scale [Tukachinsky, 2010]

$(1=$ Strongly Disagree; 7 = Strongly Agree $)$

Friends communication subscale

1. If [piped text] was a real person, I could have disclosed negative things about myself honestly and fully (deeply) to him/her.

2. If [piped text] was a real person, I could have disclosed a great deal of things about myself to [piped text].

3. Sometimes, I wish I knew what [piped text] would do in my situation.

4. If [piped text] was a real person, I could have disclosed positive things about myself honestly and fully (deeply) to him/her.

5. Sometimes, I wish I could have asked [piped text] for advice.

6. I think [piped text] could have been a friend of mine.

\section{Friends Support Subscale}

7. If [piped text] was a real person, I would have been able to count on him/her in times of need.

8. If [piped text] was a real person, I would have given him/her emotional support.

9. If [piped text] was a real person, he/she would have been able to count on me in times of need.

10. If [piped text] was a real person, I would have been willing to share my possessions with him/her.

11. If [piped text] was a real person, I could have trusted him/her completely.

12. If [piped text] was a real person, I could have had a warm relationship with him/her.

13. I wanted to promote the well-being of [piped text].

cPAX Scale [adapted from Banks et al., 2019]

( 1 =Strongly Diagree; 7 = Strongly Agree $)$

Relational Closeness

1. I felt very close to [piped text].

2. I was emotionally invested in [piped text]. 
3. I had a meaningful connection with [piped text].

4. [piped text] and I had a close relationship.

Anthropomorphic Autonomy

5. [piped text] had its own thoughts and ideas.

6. [piped text] had its own feelings.

7. [piped text] was autonomous and acted on its own.

8. [piped text] had its own sense of right and wrong.

\section{Critical Concern}

9. I paid attention to errors or contradictions in [piped text]'s world.

10. It was important to check for inconsistencies in [piped text]'s game.

11. I concentrated on inconsistencies in [piped text]'s story.

Sense of Control

12. [piped text] responded to my inputs as I expected.

13. My commands had a visible impact on [piped text]'s actions.

14. I affected [piped text] directly.

15. I was in charge of what [piped text] did.

\section{[PAGE BREAK]}

Identification [Adapted from Cohen, 2001]

(1 Strongly Disagree; 7 Strongly Agree)

1. While playing [piped text] as [piped text], I felt as if I was a part of the action.

2. While playing [piped text] as [piped text], I forgot myself and was fully absorbed.

3. I was able to understand the events in [piped text] in a manner similar to that in which [piped text] understood them.

4. I think I have a good understanding of [piped text].

5. I tended to understand the reasons why [piped text] did what he or she did.

6. While playing [piped text] as [piped text], I could feel the emotions [piped text] portrayed.

7. While playing, I felt I could really get inside [piped text]'s head.

8. At key moments in the game, I felt I knew exactly what [piped text] was going through.

9. While playing [piped text], I wanted [piped text] to succeed in achieving his or her goals.

10. When [piped text] succeeded I felt joy, but when he/she failed, I was sad.

\section{Identification Items Created for this Study}

While playing [piped text], I saw things through [piped text]'s eyes.

While playing [piped text], I sometimes felt like I was [piped text].

While playing [piped text], there were times I forgot that I was separate from [piped text]. While playing [piped text], it felt like [piped text] was me.

[PAGE BREAK] 


\section{Character Death Description}

Now, we would like you to spend some time thinking about and reporting on the death of [piped text]. Please spend a moment and try to remember what happened and how it made you feel. Describe as much as you can about the death experience in the space below.

First, please explain the circumstances around [piped text]'s death. How did [piped text] die? What happened? Please provide as much detail as you can in the space below.

We would also like to know more about your reaction to this death. Please try to picture yourself after the death occurred. Recreate the scene in your head. Below, for the next few minutes, please explain the thoughts and emotions you experienced after [piped text]'s death. What were you thinking when [piped text] died? How did you feel? Again, any information you can provide will be helpful.

\section{Mortality Salience}

For this next section, we are going to switch gears. Instead of answering questions about yourself, we would like you to complete a brief word task.

Below you will find a list of incomplete words. Please complete each word by indicating how you would fill in the blank. Please fill in one letter per each blank. Some words may be plural.

Death-thought Accessibility [Adapted from Greenberg et al., 1994]

1. $\mathrm{KI}_{-}$ED (could be killed or kissed)

2. PLA _-

3. $\mathrm{D}_{--} \mathrm{R}$

4. $\mathrm{DE}_{--} \quad$ (could be dead or deer)

5. WAT --

6. MU _-

7. GRA _ (could be grave or grass)

8. B _ TLE

9. $\mathrm{M}_{-} \mathrm{J}_{-} \mathrm{R}$

10. $\mathrm{SK}_{--} \mathrm{L}$ (could be skull or skill)

11. $\mathrm{FL}_{-} \mathrm{W}_{-} \mathrm{R}$

12. $\mathrm{LO}_{--}$ 
13. $\mathrm{COFF}_{--}$(could be coffin or coffee)

14. CHA

15. $\mathrm{TO}_{--}$(could be tomb or tool)

16. $\mathrm{CL}_{--} \mathrm{K}$

17. $\mathrm{TAB}$

18. $\mathrm{CO}_{-}{ }_{-} \mathrm{SE}$ (could be corpse or course)

19. $\mathrm{P}_{-}$TURE

20. TR

\section{[PAGE BREAK]}

\section{Grief}

Going back to thinking of [piped text]'s death, please indicate how much you agree with the following statements about your experience when [piped text] died on a scale ranging from 1 (Strongly Disagree) to 7 (Strongly Agree).

Texas Revised Inventory of Grief [adapted from Faschingbauer et al., 1987]

Past Behavior

$(1=$ Strongly Disagree; $7=$ Strongly Agree $)$

1. After [piped text] died, I found it hard to get along with people.

2. I found it hard to work well after [piped text] died.

3. After [piped text]'s death, I lost interest in my family, friends, and outside activities.

4. I felt a need to do things that [piped text] had wanted to do.

5. I was unusually irritable after [piped text] died.

6. I couldn't keep up with my normal activities for the first 3 months after [piped text] died.

7. I was angry that [piped text] left me.

8. I found it hard to sleep after [piped text] died.

Present Feelings

9. I still cry when I think of [piped text].

10. I still get upset when I think about [piped text].

11. I cannot accept [piped text]'s death.

12. Sometimes, I very much miss [piped text].

13. Even now, it's painful to recall memories of [piped text].

14. I am preoccupied with thoughts (often think) about [piped text].

15. I hide my tears when I think about [piped text].

16. No one will ever take the place of [piped text] in my life.

17. I can't avoid thinking about [piped text].

18. I feel it's unfair that [piped text] died.

19. Things and people around me still remind me of [piped text].

20. I am unable to accept the death of [piped text].

21. At times, I still feel the need to cry for [piped text]. 


\section{[PAGE BREAK]}

\section{Responses to the Game}

Now, we would like to know a bit more about what you thought about playing [piped text]. Please indicate how much you agree with the following statements about your play experience on a scale ranging from 1 (Strongly Disagree) to 7 (Strongly Agree).

\section{Appreciation/Enjoyment [Adapted from Oliver \& Bartsch, 2010]}

(1 = Strongly Disagree; 7 = Strongly Agree; $)$

Enjoyment

1. My experience playing [piped text] was fun.

2. I had a good time with my [piped text] play experience.

3. My experience with [piped text] was entertaining.

Appreciation

4. I found my experience playing [piped text] to be very meaningful.

5. I was moved by my experience playing [piped text].

6. My experience playing [piped text] was thought-provoking.

\section{[PAGE BREAK]}

\section{Trait Variables}

Now, we would like to know a bit more about how you respond, in general, to stressful events. Please indicate how much you agree with the following statements regarding how often you undergo the following behaviors on a scale ranging from 1 (Strongly Disagree) to 7 (Strongly Agree).

\section{Meaning Making [Gan et al., 2013]}

Meaning Making Subscale

1. I usually consider why stressful events happened when they do.

2. I usually consider why stressful events happen to me.

3. I usually consider the reasons why stressful events happen.

4. I usually wonder whether there is some special meaning in the occurrence of stressful events.

\section{Acceptance}

5. I usually accept the fact that somethings happen and that they cannot not be changed.

6. I usually learn to accept stressful events, and they become a part of my life.

7. I usually accept the fact that things change after stressful events.

We would also like to know why you tend to play the video games that you play. Again, please indicate how much you agree with the following statements on a scale ranging from 1 (Strongly Disagree) to 7 (Strongly Agree).

Eudaimonic/Hedonic Motivations [Adapted from Oliver \& Raney, 2011] ( 1 = Strongly Disagree; 7 = Strongly Agree; $\mathrm{E}=$ eudaimonic; $\mathrm{H}=$ hedonic $)$ 
1. I like games that challenge my way of seeing the world. [E]

2. I like games that make me more reflective. [E]

3. I like games that focus on meaningful human conditions. [E]

4. My favorite kinds of games are ones that make me think. [E]

5. I am very moved by games that are about people's search for greater understanding in life. [E]

6. I like games that have profound meanings or messages to convey. [E]

7. It's important to me that I have fun when playing a game. [H]

8. Games that make me laugh are among my favorites. [H]

9. I find that even simple games can be enjoyable as long as they are fun. $[\mathrm{H}]$

10. I like games that may be considered "silly" or "shallow" if they can make me laugh and have a good time. $[\mathrm{H}]$

11. For me, the best games are ones that are entertaining. $[\mathrm{H}]$

12. My favorite kinds of games are happy and positive. $[\mathrm{H}]$

\section{[PAGE BREAK]}

We have a few more questions about why you tend to play the video games that you play. Again, please indicate how much you agree with the following statements on a scale ranging from 1 (Strongly Disagree) to 7 (Strongly Agree).

Video Game Uses and Gratifications Instrument [Adapted from Sherry et al., 2006] ( 1 = Strongly Disagree; 7 = Strongly Agree $)$

Competition

1. I like to play to prove to my friends that I am the best.

2. When I lose to someone, I immediately want to play again in an attempt to beat him/her.

3. It is important to me to be the fastest and most skilled person playing the game.

4. I get upset when I lose to my friends.

\section{Challenge}

5. I feel proud when I master an aspect of a game.

6. I find it very rewarding to get to the next level.

7. I play until I complete a level or win a game.

8. I enjoy finding new and creative ways to work through video games.

\section{Social Interaction}

9. My friends and I use video games as a reason to get together.

10. Often, a group of friends and I will spend time playing video games.

11. I enjoy having meaningful conversations with other players while playing.

\section{Diversion}

12. I play video games when I have other things to do.

13. I play video games instead of other things I should be doing.

14. I play video games to distract myself from stressors in my life. 


\section{Fantasy}

15. I play video games because they let me do things I can't do in real life.

16. I play video games because they allow me to pretend I am someone/somewhere else.

17. I like to do something that I could not normally do in real life through a video game.

18. I enjoy the excitement of assuming an alter ego in a game.

\section{Arousal}

19. I find that playing video games raises my level of adrenaline.

20. I play video games because they keep me on the edge of my seat.

21. I play video games because they stimulate my emotions.

22. I play video games because they excite me.

\section{[PAGE BREAK]}

\section{Demographics}

Almost done! Now, we would like to ask just a few more questions about who you are as a person and as a player. If you feel uncomfortable answering any question below, please leave the response box for that question blank.

Age

How old are you today? (in years) [Will use a Qualtrics slider.]

\section{Biological Sex}

What is your biological sex?

1. Male

2. Female

3. Non-Binary

4. Prefer not to say

\section{Ethnicity}

With which ethnicity do you most closely identify? (select one)

1. Asian/Asian American

2. Black

3. Hispanic/Latino

4. Middle Eastern

5. Native American

6. White/Caucasian

7. Other [please specify]

\section{Geographical Location}

Do you currently live in the United States? Yes/No

If "Yes": If you live in the United States, in what state do you currently reside?

If "No": If you do not currently reside in the United States, in what country do you live? 


\section{Average Time Spent Playing Video Games}

Weekdays

On weekdays (Monday through Friday), how many days do you usually play video games?

1. 1 Day

2. 2 Days

3. 3 Days

4. 4 Days

5. 5 Days

On an average weekday, how long do you usually spend playing video games? (in hours) [Will use a Qualtrics slider.]

\section{Weekends}

On weekends (Saturday through Sunday), how many days do you usually play video games?

1. 1 Day

2. 2 Days

On an average day on the weekend, how long do you usually spend playing video games? (in hours) [Will use a Qualtrics slider.]

\section{Perceived Player Skill [Adapted from Matthews, 2015]}

Please indicate your level of agreement with the following statements on a 1 (Strongly

Disagree) to 7 (Strongly Agree) scale. $(\mathrm{R}=$ reverse-coded)

1. Games are often difficult to play. (R)

2. I usually worry that I won't be able to beat games when I play them. (R)

3. When I play video games, I set the difficulty higher than the default difficulty level.

4. I am very skilled at playing video games.

\section{Frequency of Playing PD Games (Yearly)}

Roughly, how many games with permadeath mechanics would you say you have played in the last year? Remember, permadeath is defined as characters permanently dying when they lose all their health, and when players cannot use that character anymore in subsequent play attempts.

0 - None

1 - Between 1 and 3 games

2 - Between 4 and 6 games

3 - Between 7 and 9 games

4 - More than 10 games 


\section{Playing PD Games Rather than PDRR Games}

Please indicate the extent you agree with this statement: I would rather play a game with permadeath mechanics in it than another game without permadeath mechanics.

( 1 = Strongly Disagree; 7 = Strongly Agree $)$

\section{[PAGE BREAK]}

\section{Closing Remarks and Gift Card Drawing Link}

Thank you again for participating in our survey! We appreciate your help and look forward to reading your responses.

If you would like to be entered in this study's gift card drawing, please provide your preferred email address at the following link:

https://wvu.qualtrics.com/jfe/form/SV_ehSPEoLYc5AT7k9

Have a nice day, and happy gaming!

[SEPARATE QUALTRICS PAGE]

\section{Email Drawing Survey}

Thank you again for participating in our survey!

After the data collection for this study is complete, we will conduct a drawing to give away 8 gift cards (\$100 each) for Amazon.com.

Please note you will only be contacted in the event that your email is drawn in order to give you instructions for redeeming your gift card. Your email will not be used for any other purposes.

If you have any questions, please email Mckay Steven West (msw0020@ mix.wvu.edu)

If you wish to be entered in the gift card drawing, please enter your preferred email here: 